\title{
Limitations of Osmotic Gradient Resource and Hydraulic Pressure on the Efficiency of Dual Stage PRO Process
}

\author{
Ali Altaee*1, \\ ${ }^{1}$ University of Technonolgy in Syndey, 15 Braodway, Ultimo, Sydney, NSW 2007, Australia, \\ Email : ali.altaee@uts.edu.au \\ Guillermo Zaragoza² \\ ${ }^{2}$ CIEMET, Plataforma Solar de Almería, Ctra. de Senés s/n, 04200 Tabernas, Almería, Spain. \\ Graeme J. Millar ${ }^{3}$ \\ ${ }^{3}$ School of Chemistry, Physics and Mechanical Engineering, Science and Engineering Faculty, \\ Queensland University of Technology (QUT), Brisbane, Queensland 4000, Australia
}

Adel O. Sharif ${ }^{4}$

${ }^{4}$ School and Chemical Engineering, Surrey University, Guildford, Surrey GU2 7XH, UK.

\section{Adnan Alhathal Alanezi ${ }^{5}$}

${ }^{5}$ Department of Chemical Engineering Technology, College of Technological Studies, The Public Authority for Applied Education and Training (PAAET), P.O. Box 117, Sabah AlSalem 44010, Kuwait

A dual stage PRO process has been proposed for power generation from a salinity gradient across a semi-permeable membrane. Both closed-loop and open-loop dual stage PRO system were evaluated using $2 \mathrm{M} \mathrm{NaCl}$ and Dead Sea as draw solutions, whereas the feed solution was either fresh water or seawater. The impact of feed salinity gradient resource and feed pressure on the net power generation and water flux were evaluated. The results showed that power density in stage one reached a maximum amount at $\Delta P=\pi / 2$, but the maximum net power generation occurred at $\Delta P<\pi / 2$. This result was mainly attributed to the variation of net driving pressure in stage one and two of the PRO process. The dual stage PRO process was found to perform better at high osmotic pressure gradient across the PRO membrane, for example when Dead Sea brine or highly concentrated $\mathrm{NaCl}$ was the draw solution. Total power generation in the dual stage PRO process was up to $40 \%$ higher than that in the conventional PRO process. This outcome was achieved through harvesting the rest of the energy remaining in the diluted draw solution. Therefore, a dual stage PRO process has the potential of maximizing power generation from a salinity gradient resource. 
Keywords: Dual stage; Pressure Retarded Osmosis; Renewable energy; High efficiency; Osmotic energy

*Corresponding author

University of Technonolgy in Syndey, 15 Braodway, Ultimo, Sydney, NSW 2007, Australia,; Telephone +61420606500

Email: ali.altaee@uts.edu.au 


\section{Introduction}

Pressure Retarded Osmosis (PRO) is a membrane based process for power generation which involves the transport of water across a semi-permeable membrane separating two solutions of different osmotic pressures $[1,2]$. Statkraft have pioneered the development of PRO since 1997, especially in relation to enhancement of both membrane flux and salt retention [1]. Several pilot plants have been constructed worldwide to test the emerging concept of PRO and its potential application for power generation [3-5]. Using innovative membranes of high water flux has resulted in a satisfactory performance and encouraged efforts toward commercialization $[3,6]$. Membrane power densities in excess of $5 \mathrm{~W} / \mathrm{m}^{2}$, a theoretical threshold value to achieve an economical PRO process, have been reported in a number of laboratory and pilot plant studies $[1,7,8]$.

The osmotic gradient resource is one of the key parameters in the PRO process as it has significant influence upon the process performance. For example, seawater and fresh water have been proposed as the draw and feed solutions in the PRO process [9-11]. However, insufficient membrane flux has been reported due to the inability of the membrane to effectively operate $[9,12,13]$. Factors such as Concentration Polarization (CP) and membrane fouling often develop during the filtration process resulting in a negative impact on the membrane flux. Membrane fouling by organic matters has been found to be more aggressive at recovery rates over $80 \%$ using seawater and fresh water as the draw and feed solutions, respectively [13]. Osmotic power plant in Norway suffered from inadequate membrane flux due to insufficient osmotic pressure gradient [8]. Lack of sufficient membrane flux and hence power density $\left(\sim 4 \mathrm{~W} / \mathrm{m}^{2}\right)$, was among the reasons for pilot plant unsatisfactory performance and closure. Pilot plant tests with RO concentrated brine and wastewater effluent as the draw and feed solutions, respectively, have alternatively demonstrated a promising membrane power density of $7.7 \mathrm{~W} / \mathrm{m}^{2}$ at a 25 bar hydraulic pressure [3] using a modified, four port Toyobo Hollow Fibre (THF) membrane in the PRO process. The Mega-ton water project is another successful example of using PRO process for power generation [14]. The Osmotic power plants used RO concentrated brine as the draw solution and 30 bar hydraulic pressure. Ten inch diameter Toyobo HF membrane was used in the membrane module yielding a membrane power density of $13.3 \mathrm{~W} / \mathrm{m}^{2}$. The successful implementation of Megaton pilot plants was mainly attributed to the 
considerable osmotic driving pressure generated by concentrated RO brine and enabled 30 bar hydraulic pressure to be applied across the membrane. Theoretical studies by Avi suggested that a power density of $55.6 \mathrm{~W} / \mathrm{m} 2$ could be achieved by coupling seawater (4.2\%) with seawater brine (25\%) and using HTI FO membrane [15]. The study proposed a closed-loop PRO for power generation and seawater water desalination that is able to desalinate $377 \mathrm{~m}^{3} / \mathrm{d}$ of SW. Special importance, therefore, should be given to the salinity gradient resource in the PRO process. For a given hydraulic pressure, power density can be increased by increasing the Net Driving Pressure (NDP) across the PRO membrane module or membrane permeability [11]. Mega-ton, for example, has demonstrated considerably high power density due to the significant salinity gradient resource.

Draw solution should have high osmotic pressure, be cheap, and readily available [11]. Concentrated RO brine, seawater, ammonium/carbon dioxide mixtures and Dead Sea brine (also denoted as DSB), Rift valley water, Jordan water, have all been proposed as draw solutions $[3,7,8,14,16]$. Upon pairing with a lower osmotic pressure feed solution; the available salinity gradients have been used for power generation using either closed-loop or open-loop PRO processes [16] [Figure 1]. Draw solution, such as ammonium carbon dioxide or $\mathrm{NaCl}$, is pressurized and fed into the PRO for fresh water extraction from feed solution such as fresh water or seawater [Figure 1A]. The diluted draw solution splits into two streams after leaving the first stage of the PRO membrane. Stream number one returns to Pressure Exchanger $(\mathrm{PX})$ to pressurize the draw solution while stream number two is fed into the second stage PRO process for fresh water extraction from the feed solution. Finally, the pressurized draw solution from the second stage of the PRO process goes to the turbine system for power generation. After leaving the turbine system, the diluted draw solution goes to the regeneration unit, thermal or membrane, for regeneration and fresh water extraction. The main difference between closed and open-loop PRO process is that diluted draw solution is disposed of after leaving the turbine system [Figure 1B] in the open-loop PRO process. In this case, the draw solution could be seawater or a brine waste stream such as concentrated RO brine. However, PRO performance increases with increasing osmotic pressure difference across the membrane and hence it is desirable to use high salinity seawater [11]. For example, with salinity over $300 \mathrm{~g} / \mathrm{L}(\sim 5 \mathrm{M} \mathrm{NaCl})$, the osmotic pressure of Dead Sea brine is about 8 times higher than that of seawater. Practically, the actual 
concentration of Dead Sea would be around $3 \mathrm{M} \mathrm{NaCl}$ due to the considerable concentrations of divalent ions [17]. As proposed by Loeb [16], the diluted Dead Sea brine from the PRO process returns back to the Dead Sea to replenish the evaporation rate from the Dead Sea. Therefore, concentrated RO brine and Dead Sea water have been proposed as the feed and draw solution of the PRO process. Theoretically, this is possible when the RO plant is operating in proximity to the PRO plant.

Earlier studies [16, 17] showed that diluted Dead Sea brine would still be highly concentrated after leaving the PRO module. Therefore, the energy possessed by the diluted Dead Sea brine can potentially be harvested by a second stage PRO system. In the present work, a dual stage PRO process was proposed for power generation from a draw solution more concentrated than seawater using closed-loop and open-loop PRO process to maximize power generation from the proposed gradient resource. $2 \mathrm{M} \mathrm{NaCl}$-fresh water and $2 \mathrm{M} \mathrm{NaCl}-0.5 \mathrm{M} \mathrm{NaCl}$ (resembling seawater TDS) salinity gradients were used in the closed-loop dual stage PRO process. In the open-loop dual stage PRO process, Dead Sea brine and seawater (TDS between 32 and $50 \mathrm{~g} / \mathrm{L}$ ) were used as the draw and feed solutions, respectively. The impact of feed solution salinity, and operational parameters such as hydraulic pressure on the PRO performance was evaluated using a pre-developed model $[10,11]$. High water flux across the PRO membrane results in concentrative and dilutive concentration polarizations, respectively, at the feed and draw solution sides of the membrane [16]. The impact of internal and external concentration polarization on the membrane flux was estimated using previously published mathematical expressions [17-19]. It should be noted that these models are less accurate upon scaling-up and application on full scale PRO membrane module. Furthermore, reverse salt diffusion from the draw to feed side was estimated in the closed-loop PRO. Reverse salt diffusion results in a draw solution loss which is particularly important when a custom-designed draw solution is used in an open-loop process. The osmotic pressure of feed and draw solution were estimated, for simplicity, from the Van't Hoff equation although it is less accurate at high feed concentrations. This inherent inaccuracy may result in a membrane flux lower than planned. Finally, it was assumed here that pressure losses in the system were negligible and hence the hydraulic pressure of stage two was equal to that of stage one. 


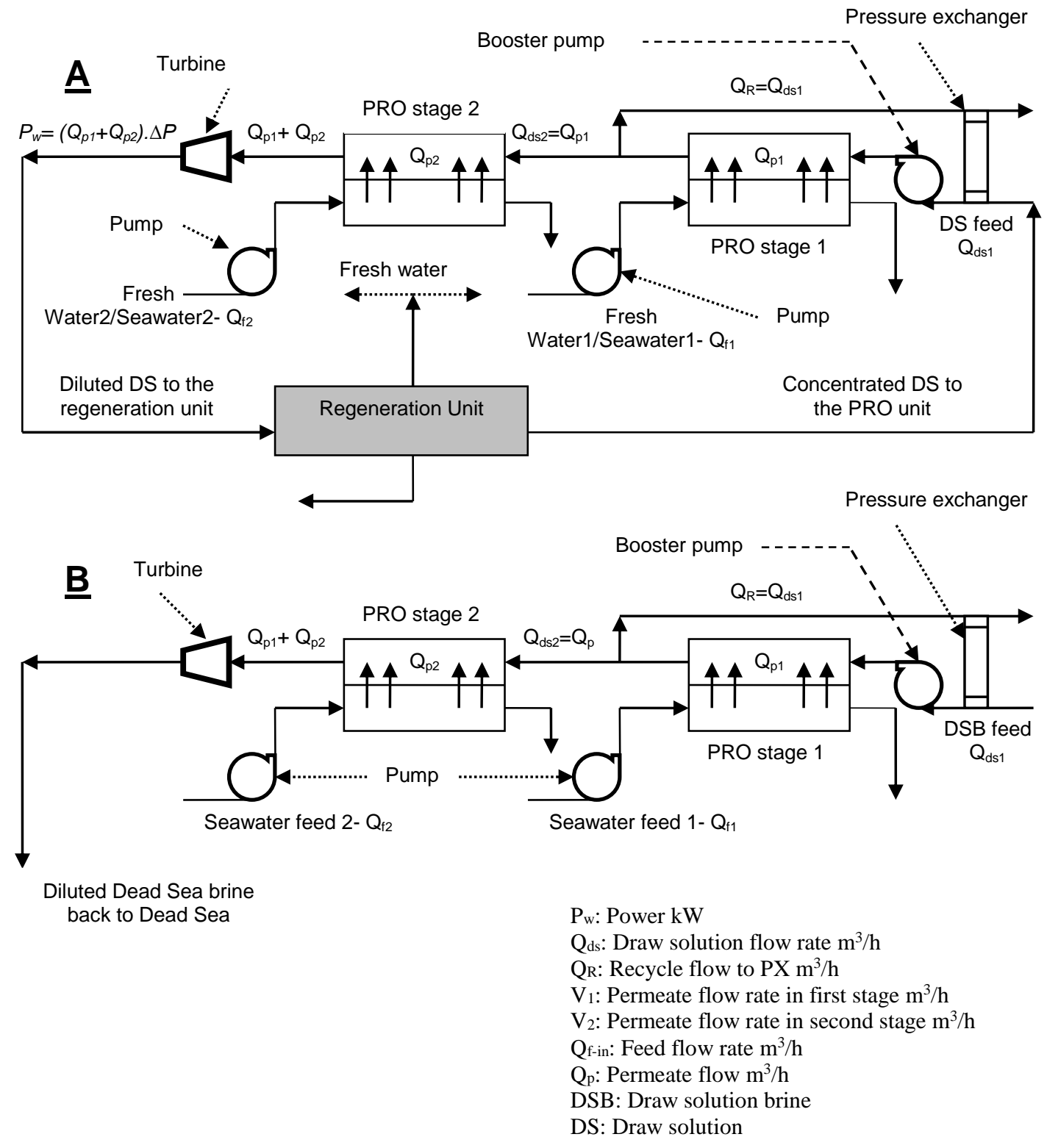

Figure 1: Schematic diagram of dual stage PRO process a) closed-loop dual stages PRO units, PX in stage one, and turbine located after stage 2 , freshwater or seawater feed, inorganic draw solution b) open-loop dual stages PRO units, PX in stage one, and turbine located after stage 2, seawater feed, Dead Sea draw solution, pumps efficiency is assumed 0.8 


\section{Methodology}

\subsection{Osmotic energy of concentrated draw solution and Seawater}

Defined as the power generated per square meter of membrane $\left(\mathrm{W} / \mathrm{m}^{2}\right)$, power density $(W)$ has been used as an indicator of the PRO process performance [18]. The expression used to calculate power density is as shown in Equation 1:

Equation $1 \quad W=\Delta P^{*} J_{w}$

Where, $\Delta P$ is the hydraulic pressure difference across the membrane (bar) and $J_{w}$ is the membrane flux $\left(\mathrm{L} / \mathrm{m}^{2} \mathrm{~h}\right)$. In the dual stage PRO process, permeate flow from stage one, $Q p_{1}$, is the draw solution of stage two. Practically, $Q_{p 1}$ is lower than $Q_{f 1}$ [Figure 1] therefore the membrane area required for draw solution treatment in stage two is less than that for stage one. The cumulative permeate flow from the first and second stage of the PRO process goes to a turbine system for power generation. Gross power generation from the single (conventional) and the dual stage PRO processes are described in Equations 2 and 3, respectively.

Equation 2

$$
P_{w-\text { single }}=\Delta P * Q_{p 1}
$$

Equation 3

$$
P_{w-d u a l}=\Delta P *\left(Q_{p 1}+Q_{p 2}\right)
$$

$P_{w-s i n g l e}$ and $P_{w-d u a l}$ represent the power generation from single and dual stage PRO processes, respectively (kW), $\Delta P$ is the hydraulic pressure difference (bar), and $Q_{p 1}$ and $Q_{p 2}$ are the first and second stage permeate flow rates, respectively $\left(\mathrm{m}^{3} / \mathrm{h}\right)$. Net power generation in the PRO process was equal to the difference between total power generation and power consumption which was incurred due to feed and draw solution pumping. The specific energy consumption per unit volume of product water $E s\left(\mathrm{kWh} / \mathrm{m}^{3}\right)$, of the first and second stage of the PRO process was calculated from the Equation 4 [20]:

Equation 4

$$
E s_{n}=\frac{\left(P_{f n} * Q_{f n}\right)+\left(P_{d s n} * Q_{d s n}\right)}{\eta^{*} Q_{p n}}
$$


In equation $4, P_{f}$ and $P_{d s}$ are the hydraulic pressures of feed and draw solution (bar), $Q_{f}$ and $Q_{d s}$ are the feed and draw solution flow rates $\left(\mathrm{m}^{3} / \mathrm{h}\right), \eta$ is pump efficiency ( $\left.\sim 0.8\right)$, and $\mathrm{n}$ is the stage number. Total permeate flow rate in the dual stage PRO process was determined from the mass balance equation [Equation 5].

Equation 5

$$
Q_{p t}=\left(\frac{Q_{d s-i n 1}}{Q_{d s-i n 1} / Q_{f-i n 1}}\right) \% \operatorname{Re}_{1}+\left(\frac{Q_{d s-i n 1} * \% \operatorname{Re}_{1}}{Q_{d s-i n 2} / Q_{f-i n 2}}\right) \% \operatorname{Re}_{2}
$$

Where $\% \operatorname{Re}_{1}$ and $\% \mathrm{Re}_{2}$ are the first and second stage recovery rates, $Q_{f-\text { in } 1}$ and $Q_{f-\text { in2 }}$ are the first and second stage feed flow rates $\left(\mathrm{m}^{3} / \mathrm{h}\right)$, and $Q_{d s-i n 1}$ and $Q_{d s-i n 2}$ are the first and second stage draw solution flow rates $\left(\mathrm{m}^{3} / \mathrm{h}\right)$. Theoretically, the minimum power density to achieve an economically feasible PRO process is $5 \mathrm{~W} / \mathrm{m}^{2}$. However, a $W$ value of $5 \mathrm{~W} / \mathrm{m}^{2}$ can't be maintained in the long-term due to membrane deterioration over time. Figure 2 shows the maximum power density of PRO process using Dead Sea or seawater as draw solution.

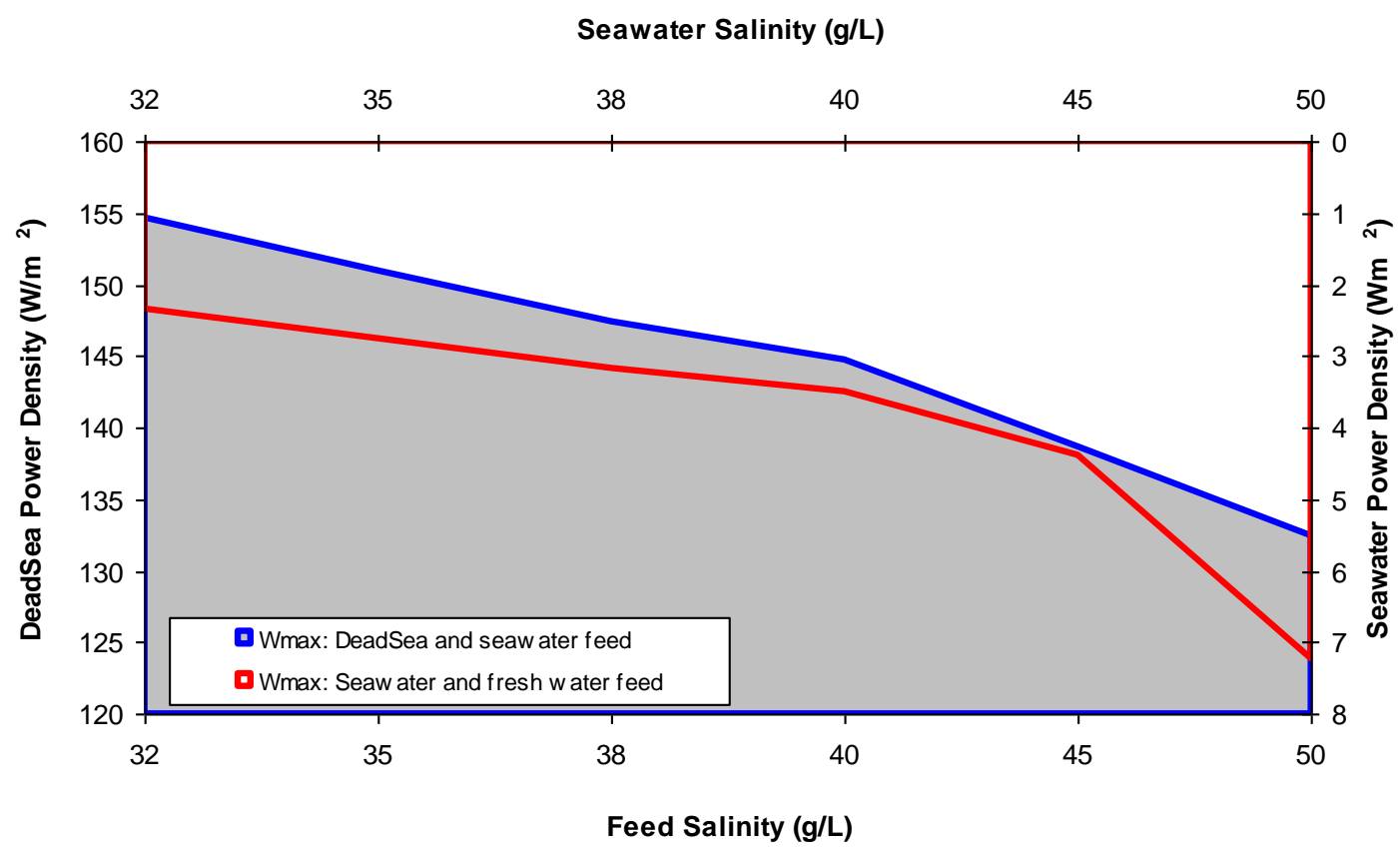

Figure 2: PRO power density of Dead Sea and Seawaters. (PRO membrane is CTA membrane, HTI Company, and feed pressure $\Delta P=\Delta \pi / 2$ )

Cellulose Triacetate (CTA) membrane (HTI, USA) was applied to estimate water flux in Figure 2. The osmotic pressure of seawater at $35 \mathrm{~g} / \mathrm{L}$ salinity was about 26 bar [11]; theoretically, it 
is able to generate a maximum power density, i.e. $\Delta P=\pi / 2$, of $2.7 \mathrm{~W} / \mathrm{m}^{2}$ when it is coupled with fresh water as the salinity gradient resource [Figure 2]. When Dead Sea brine (osmotic pressure 216 bar) was coupled with seawater as the draw and feed solutions respectively, power density of the PRO process decreased with increasing seawater salinity. On the contrary, power density of the PRO process increased with increasing seawater salinity when seawater was coupled with freshwater as the draw and feed solutions, respectively. The maximum power density, $W_{\max }$, of Dead Sea-seawater salinity gradient resource was 21 times higher than the $W_{\max }$ of a seawater-freshwater salinity gradient resource [Figure 2]. Practically, power consumption in the PRO module should be accounted for and deducted from the gross power generation by PRO process. Figure 3 illustrates the theoretical gross and net power generation in the PRO process. The net power generation was approximately $67 \%$ of the gross power generation in the dual stage PRO process. However, the maximum power density can be increased $>2.5$ times when the TDS of seawater is $50 \mathrm{~g} / \mathrm{L}$ [Figure 2]. As a result of dilution, the TDS of seawater will reduce from 50 to $27 \mathrm{~g} / \mathrm{L}$ after leaving the PRO module and its osmotic pressure will decrease from 37 to 19 bar. In such case, the seawater will practically be an exhausted draw solution after leaving the PRO membrane. Therefore, a second stage PRO process will be economically worthless due to the insufficient osmotic energy which can be harvested from the diluted seawater.

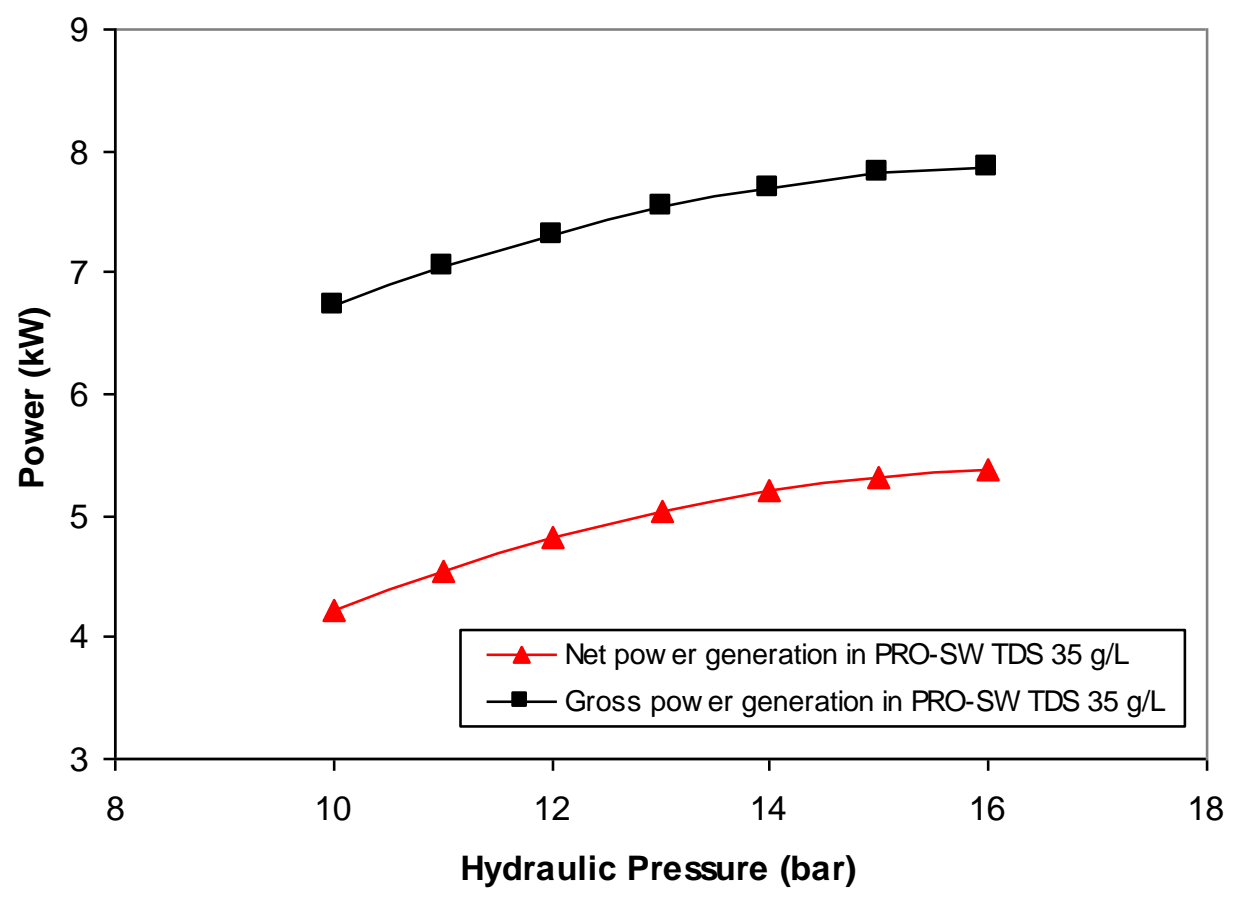


Figure 3: Theoretical gross and net power generation by the PRO process using seawaterfreshwater salinity gradient resource, seawater TDS is $35 \mathrm{~g} / \mathrm{L}$ and osmotic (pressure 26 bar).

With its elevated osmotic pressure, Dead Sea-seawater (TDS $50 \mathrm{~g} / \mathrm{L}$ ) salinity gradient resource can generate a theoretical $W_{\max }$ of $132 \mathrm{~W} / \mathrm{m}^{2}$ at 90 bar hydraulic pressure. The maximum specific energy can be generated from Dead Sea $(5 \mathrm{M} \mathrm{NaCl})$-seawater $(0.6 \mathrm{M} \mathrm{NaCl})$ is $1.37 \mathrm{kWh} / \mathrm{m} 3$ [19] and the estimated TDS and osmotic pressure of diluted Dead Sea water are $195 \mathrm{~g} / \mathrm{L}$ and 190 bar, respectively. These latter values are approximately 7.3 times higher than the osmotic pressure of normal salinity seawater (TDS $\sim 35 \mathrm{~g} / \mathrm{L}$ ). Interestingly, the osmotic energy of Dead Sea brine remains significantly high after dilution. This energy can be harvested by a second stage PRO process to increase the total power generation using diluted Dead Sea brine as draw solution. As shown in Figure 1A, this concept can also be used with thermolytic or inorganic metal salts (such as $\mathrm{MgCl}_{2}$ and $\mathrm{NaCl}$ ) as draw solution in a closed-loop dual stage osmotic power plant. Diluted draw solution from the dual stage PRO process is regenerated by a suitable membrane or thermal process. In the current study 2 $\mathrm{M} \mathrm{NaCl}$ was used as the draw solution in a closed-loop dual stage PRO process.

\subsection{High Performance Dual Stage PRO Process}

Dual stage PRO process has been initially proposed for power generation using a variety of feed sources [10]. Utilization of substantial osmotic gradient resources such as highly concentrated ionic solution and Dead Sea water may further enhance process applications. Equations 2 and 3 have been used to estimate the total power generation in the conventional and dual stage PRO processes. Power generation in the first and the second stage as a percentage of the total power generated in the dual stage of the PRO process is illustrated in Figure 4. At $\Delta P=\Delta \pi / 2$, power generation from Dead Sea-seawater (TDS 32$50 \mathrm{~g} / \mathrm{L}$ ) salinity gradient resource could be increased by 40 to $47 \%$ when a second stage PRO process was introduced [Figure 4]. The contribution of the first and second stages of the PRO process to the total power generation, $P_{w t}$, in the dual stage PRO process was about 60 and $40 \%$, respectively ( $32 \mathrm{~g} / \mathrm{L}$ seawater TDS). The contribution of the first stage PRO process decreased to $47 \%$ when the feed solution was $50 \mathrm{~g} / \mathrm{L}$. In the case of a closed-loop PRO process, $\mathrm{NaCl}$ or thermolytic solution may be used as the draw agent while seawater or fresh water is the feed water. Using a highly concentrated salinity gradient resource in the 
dual stage PRO process can significantly increase the process performance in terms of potential power generation.

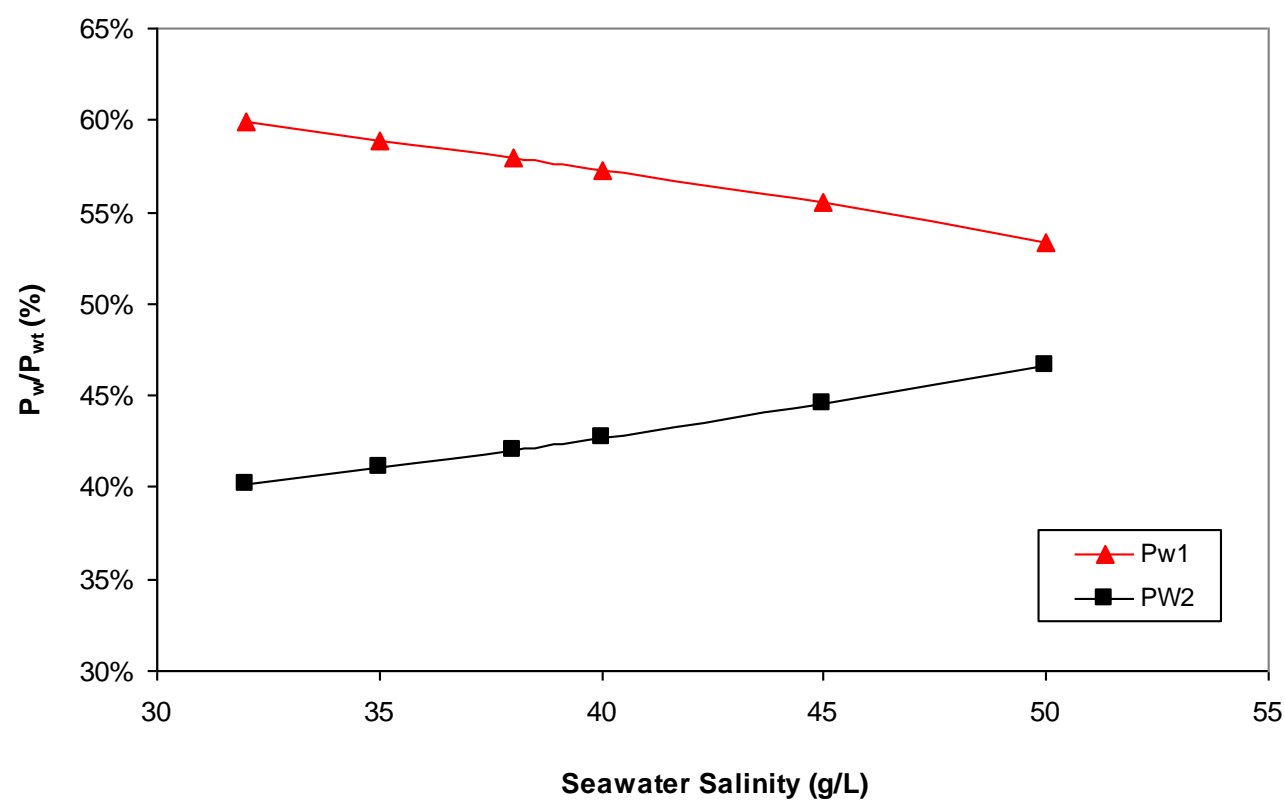

Figure 4: Percentage of power generation in the first and second stage of the stage PRO process, Dead Sea (TDS $334 \mathrm{~g} / \mathrm{L}$ ) draw solution and seawater (TDS 32-50 g/L) feed solution, $P_{w}$ was taken at $\Delta \pi / 2$.

\subsection{PRO process modelling}

Dead Sea brine and $2 \mathrm{M} \mathrm{NaCl}$ were evaluated as draw solutions in the PRO process while the feed solution was fresh water, $\mathrm{NaCl}$ solution, or seawater [Figure 1]. The compositions of Dead Sea brine and seawater are shown in Table 1 [21]. The Van't Hoff Equation was used to predict the osmotic pressure of the draw and feed solutions. Water flux, $J_{w}$, was estimated from Equation 6:

Equation 6

$$
J_{w}=A_{w} *(\Delta \pi-\Delta P)
$$

In equation $6, A_{w}$ is the coefficient of membrane permeability ( $\mathrm{L} / \mathrm{m}^{2} \mathrm{~h}$.bar), $\Delta P$ is the feed pressure difference (bar) and $\Delta \pi$ is the osmotic pressure difference across the membrane (bar). A salt diffusion coefficient, $B$, is usually calculated in an RO membrane cell as a function of membrane rejection rate and water flux [Equation 7]: 
Equation 7

$$
B=\frac{(1-R j) J_{w}}{R j}
$$

The rejection rate, $R j$, is the ratio of permeate to feed ion concentrations. Previous experiments showed that concentrative and dilutive concentration polarizations had an adverse impact on water flux in osmotically driven membrane processes [19, 22]. Typically, concentrative concentration polarization occurs at the feed solution side of the membrane whereas dilutive concentration polarization is present on the draw solution side. The impact of concentration polarization on the membrane flux can be estimated from Equation $8[12,19,22]:$

Equation 8

$$
J_{w}=A_{w}\left(\frac{\pi_{D b} e^{\left(\frac{-J_{w}}{k}\right)}-\pi_{F b} e^{\left(J_{w} K\right)}}{1+\frac{B}{J_{w}}\left(e^{\left(J_{w} K\right)}-e^{\left(\frac{-J_{w}}{k}\right)}\right)}-\Delta P\right)
$$

Where, $\pi_{D b}$ and $\pi_{F b}$ are the osmotic pressures of the bulk draw and feed solution, respectively (bar), $k$ is the mass transfer coefficient $(\mathrm{m} / \mathrm{s}), B$ is the solute permeability coefficient $\left(\mathrm{kg} / \mathrm{m}^{2} \mathrm{~h}\right)$, and $K$ is the solute resistivity for diffusion within the porous support layer $(\mathrm{s} / \mathrm{m})$. Mathematically, $k$, is calculated from Equation 9:

Equation 9

$$
k=\frac{S h D}{d_{h}}
$$

Where $S h$ is the Sherwood number, $D$ is the diffusion coefficient of the solute $\left(\sim 1.61 \times 10^{-9}\right.$ $\mathrm{m}^{2} / \mathrm{s}$ for $\mathrm{NaCl}$ ) and $d_{h}$ is the hydraulic diameter of the flow channel $(\mathrm{m})$. Previous studies showed that $k$ value varied from $3 \times 10^{-5}$ to $8 \times 10^{-5}(\mathrm{~m} / \mathrm{s})$ [19]. In the current study a $k$ value of $6.9 \times 10^{-5}(\mathrm{~m} / \mathrm{s})$ was chosen $[12,17,18,22]$. The solute resistivity to diffusion, $K$, is a function of the solute diffusion coefficient, $D$, and the membrane structural parameters, $S$ $(\mu \mathrm{m})[23]$ [Equation 10]:

Equation 10

$$
K=\frac{S}{D}
$$


In the current study, membrane structural parameter, $S$, was predicted from Equation 11 [22]:

Equation 11

$$
S=\left(\frac{D}{J_{w}}\right) \ln \left(\frac{B_{r}+A_{w} \pi_{D b}}{B_{r}+J_{w}}\right)
$$

Where, the solute permeability coefficient, $B_{r}$, was calculated on the membrane active layer assuming the membrane process was operating in a PRO mode (draw solution facing the membrane active layer) taking into account the effect of dilutive concentration polarization of draw solution at the membrane surface. The expression used to calculate $B_{r}$ in equation 11 was as shown in Equation 12 [22]:

Equation 12

$$
B_{r}=\frac{(1-R j) J_{w}}{R j} e^{\left(\frac{-J_{w}}{k}\right)}
$$

Reverse salt diffusion, $J_{s-r}\left(\mathrm{~mol} / \mathrm{m}^{2} \mathrm{~h}\right)$, from the draw solution to the feed solution is another inherent problem in osmotically driven membrane processes which results in a number of undesirable effects such as osmotic agent losses [10]. Therefore, the concentration of draw solution is maintained by adding a concentrated draw agent from a stock solution tank. Taking into account internal and external concentration polarization, $J_{s-r}\left(\mathrm{~mol} / \mathrm{m}^{2} \mathrm{~h}\right)$ was calculated using the following formula illustrated in Equation 13 [22]:

Equation 13

$$
J_{s-r}=B\left(\frac{C_{D b} e^{\left(\frac{-J_{w}}{k}\right)}-C_{F b} e^{\left(J_{w} K\right)}}{1+\frac{B}{J_{w}}\left(e^{\left(J_{w} K\right)}-e^{\left(\frac{\left.-J_{w}\right)}{k}\right)}\right)}\right)
$$

Where, $C_{D b}$ and $C_{F b}$ are the bulk concentration of draw and feed solution, respectively $(\mathrm{mg} / \mathrm{L})$. It was more convenient in the current study to use $\mathrm{mol} / \mathrm{m}^{2} \mathrm{~h}$ for describing the reverse salt diffusion, $J_{s-r}$. Cellulose Triacetate (CTA) FO membrane, HTI Company (USA), was evaluated in the present study for an osmotic power plant which had a rejection rate to $\mathrm{NaCl}$ of ca. 99\%. Hydraulic pressures between 0 and 90 bar were evaluated and were provided by a pump installed on the draw solution side of stage 1 [Figure 1]. Additionally, 
two low pressure pumps were installed on the feed solution side of the membrane. Osmotic pressure and concentration pressure of Dead Sea and seawater were calculated as shown in Table 1. It was assumed that 35 and $40 \mathrm{~g} / \mathrm{L}$ TDS represent the concentration of Mediterranean and Red sea salinity, respectively.

Table 1: Concentration and composition of feed and draw solution

\begin{tabular}{|c|c|c|c|}
\hline $\begin{array}{c}\text { Ion Concentrations } \\
(\mathbf{m g} / \mathrm{L})\end{array}$ & $\begin{array}{c}\text { Seawater } \\
(\mathbf{3 5} \mathbf{g} / \mathrm{L})\end{array}$ & $\begin{array}{c}\text { Seawater } \\
(\mathbf{4 0} \mathbf{g} / \mathbf{L})\end{array}$ & $\begin{array}{c}\text { Dead Sea } \\
(\mathbf{3 3 8} \mathbf{g} / \mathbf{L})\end{array}$ \\
\hline $\mathrm{K}$ & 387 & 441 & 7800 \\
\hline $\mathrm{Na}$ & 10778 & 12278 & 36600 \\
\hline $\mathrm{Mg}$ & 1293 & 1473 & 45900 \\
\hline $\mathrm{Ca}$ & 421 & 480 & 17600 \\
\hline $\mathrm{Cl}$ & 19406 & 22105 & 230400 \\
\hline $\mathrm{SO}_{4}$ & 2710 & 3086 & - \\
\hline $\mathrm{HCO}_{3}$ & 142 & 162 & 216.2 \\
\hline & & & 29.8 \\
\hline$\pi$ (bar) & 26.2 & & \\
\hline
\end{tabular}




\section{Results and Discussion}

\subsection{Closed-loop dual stage PRO power plant}

A closed-loop osmotic power plant was evaluated using $2 \mathrm{~mol} \mathrm{NaCl}$ draw solution [Figure 1A]. PRO membrane characteristics are listed in Table 2. Two feed concentrations, fresh water (FW) and $0.5 \mathrm{M} \mathrm{NaCl}$, were evaluated in the closed-loop PRO which simulated the concentrations of fresh water and seawater, respectively. Hydraulic pressures between 0 and 62 bar were evaluated to study the impact of feed pressure on permeate flow and power density in the PRO process [Figure 5].

Table 2: Operating parameters of the PRO process: the values of $J_{w}$ and $J_{s}$ varied with the concentration of feed and draw solutions.

\begin{tabular}{|c|c|c|}
\hline Parameter & Value & Comments \\
\hline$A\left(\mathrm{~L} / \mathrm{m}^{2} \mathrm{~h} . \text { bar }\right)^{*}$ & 0.792 & Eq. 4 \\
\hline$B_{r}\left(\mathrm{~L} / \mathrm{m}^{2} \mathrm{~h}\right)$ & $0.366-0.540$ & Eq. 10 \\
\hline$S(\mu \mathrm{m})$ & $120-497$ & Eq. 9 \\
\hline$K(\mathrm{~s} / \mathrm{m})$ & $0.25 \times 10^{5}$ & Eq. 8 \\
\hline$k(\mathrm{~m} / \mathrm{h})$ & 0.252 & Eq. 7 \\
\hline$J_{w}$ & - & Eq. 6 \\
\hline$J_{s}$ & - & Eq. 11 \\
\hline
\end{tabular}

* For CTA membrane (HTI) [12]

Figure 5a shows the power density and the membrane flux in the first and second stage of the dual stage PRO process using $2 \mathrm{~mol} \mathrm{NaCl}$ draw solution and Fresh Water (FW) feed solution. In both stages, the membrane flux, $J_{w}$, decreased with increasing feed pressure. Similar results were observed when the salinity of the feed solution increased from FW to $0.5 \mathrm{M} \mathrm{NaCl}$ [Figure 5b]. This latter result was a consequence of the lower Net Driving Pressure (NDP) across the PRO membrane at higher feed pressure [10]. In general, NDP across the membrane deceased with increasing feed pressure [Figure 6]. However, NDP was always lower in the second stage of the PRO process due to draw solution dilution in the first stage of the PRO process. Accordingly, the first stage power density, $W_{1}$, was higher than the second stage power density, $\mathrm{W}_{2}$, [Figures $5 \mathrm{a}$ and $5 \mathrm{~b}$ ). For the $2 \mathrm{M} \mathrm{NaCl}-\mathrm{FW}$ 
salinity gradient resource and 45 bar hydraulic pressure, $W_{1}$ and $W_{2}$ were 27.4 and 14.8 $\mathrm{W} / \mathrm{m}^{2}$, respectively; i.e. $\mathrm{W}_{2}$ was about $54 \%$ of magnitude of $W_{1}$.
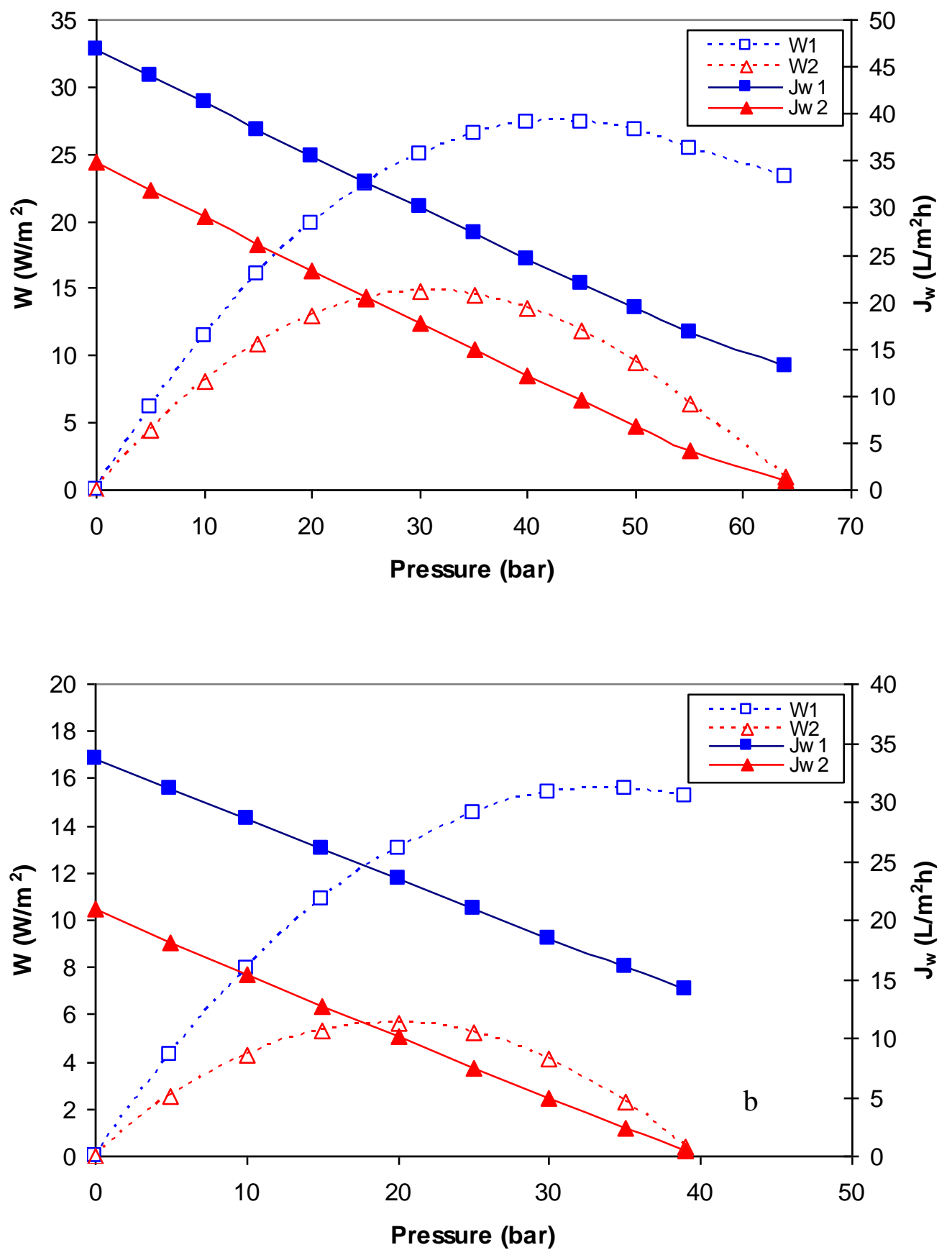

Figure 5: Impact of draw solution pressure on the membrane flux $\left(\mathrm{J}_{\mathrm{w}}\right)$ and power density (W), testing parameters are shown in table 2, (a) $2 \mathrm{M} \mathrm{NaCl}$ draw solution and fresh water, (b) $2 \mathrm{M} \mathrm{NaCl}$ draw solution and $0.5 \mathrm{M} \mathrm{NaCl}$ feed solution to represent seawater. 
When the feed concentration increased to $0.5 \mathrm{M} \mathrm{NaCl}$ and 35 bar hydraulic pressure, $\mathrm{W}_{1}$ and $W_{2}$ were 15.6 and $5.6 \mathrm{~W} / \mathrm{m}^{2}$, respectively; i.e. $W_{2}$ was approximately $36 \%$ of value for $W_{1}$. The higher $W_{1}$ in stage one was mainly attributed to higher NDP across the PRO membrane [Figure 6]. It should be mentioned that for both salinity gradient resources, $2 \mathrm{M}$ $\mathrm{NaCl}-\mathrm{FW}$ and $2 \mathrm{M}-0.5 \mathrm{M} \mathrm{NaCl}, \mathrm{W}_{1}$ reached a maximum amount at $\Delta P_{1}=\Delta \pi_{1} / 2$.

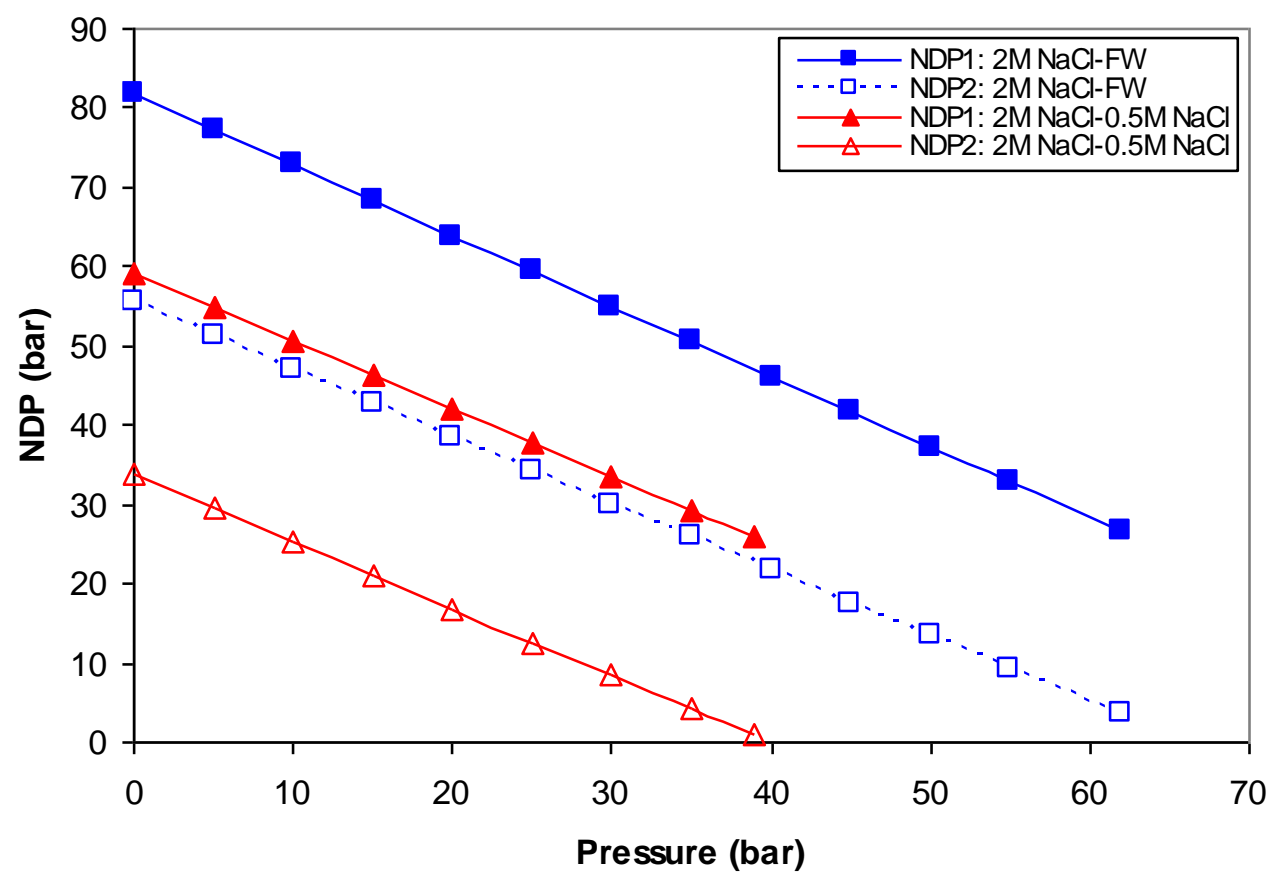

Figure 6: NDP in PRO process at different feed pressures

Draw solution reverse salt diffusion to the feed solution is an inherent phenomenon in osmotically driven membrane processes. Reverse salt diffusion results in a draw agent loss and adversely affects the performance of PRO process [8]. Figure 7a shows reverse salt flux in the first and second stage of the PRO process, $J_{s-r 1}$ and $J_{s-r 2}$, respectively. The results suggested that $J_{s-r 1}$ and $J_{s-r 2}$ increased with increasing feed pressure. This behaviour was due to the lower water flux across the membrane which resulted in a higher draw solution bulk concentration at the membrane surface. The concentration of draw solution at the membrane surface in the first and second stage of the PRO process, $C_{D-m 1}$ and $C_{D-m 2}$, respectively, was lower than that of the bulk solution, $C_{D b}$, due to the effect of dilutive concentration polarization. Mathematically, $C_{D-m}$ and $C_{F-m}$ were calculated from Equations 14 and 15: 
Equation 14

$$
C_{D-m}=C_{D b} \operatorname{Exp}\left(-\frac{J_{w}}{k}\right)
$$

Equation 15

$$
C_{F-m}=C_{F b} \operatorname{Exp}\left(J_{w} K\right)
$$

Equations 14 and 15 indicate the impact of dilutive and concentrative concentration polarization, respectively, at the draw and feed solution assuming that draw solution faces the membrane selective layer while the feed solution faces the porous support layer.

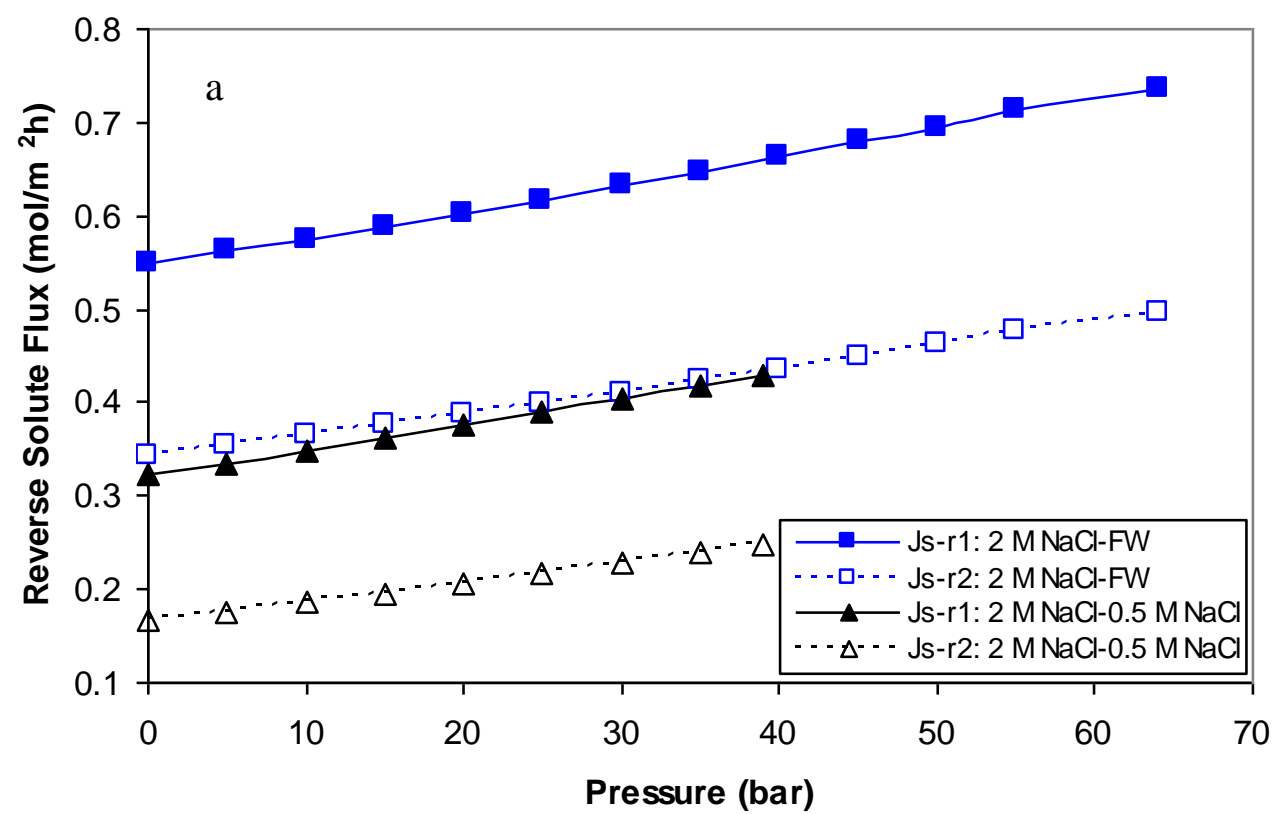



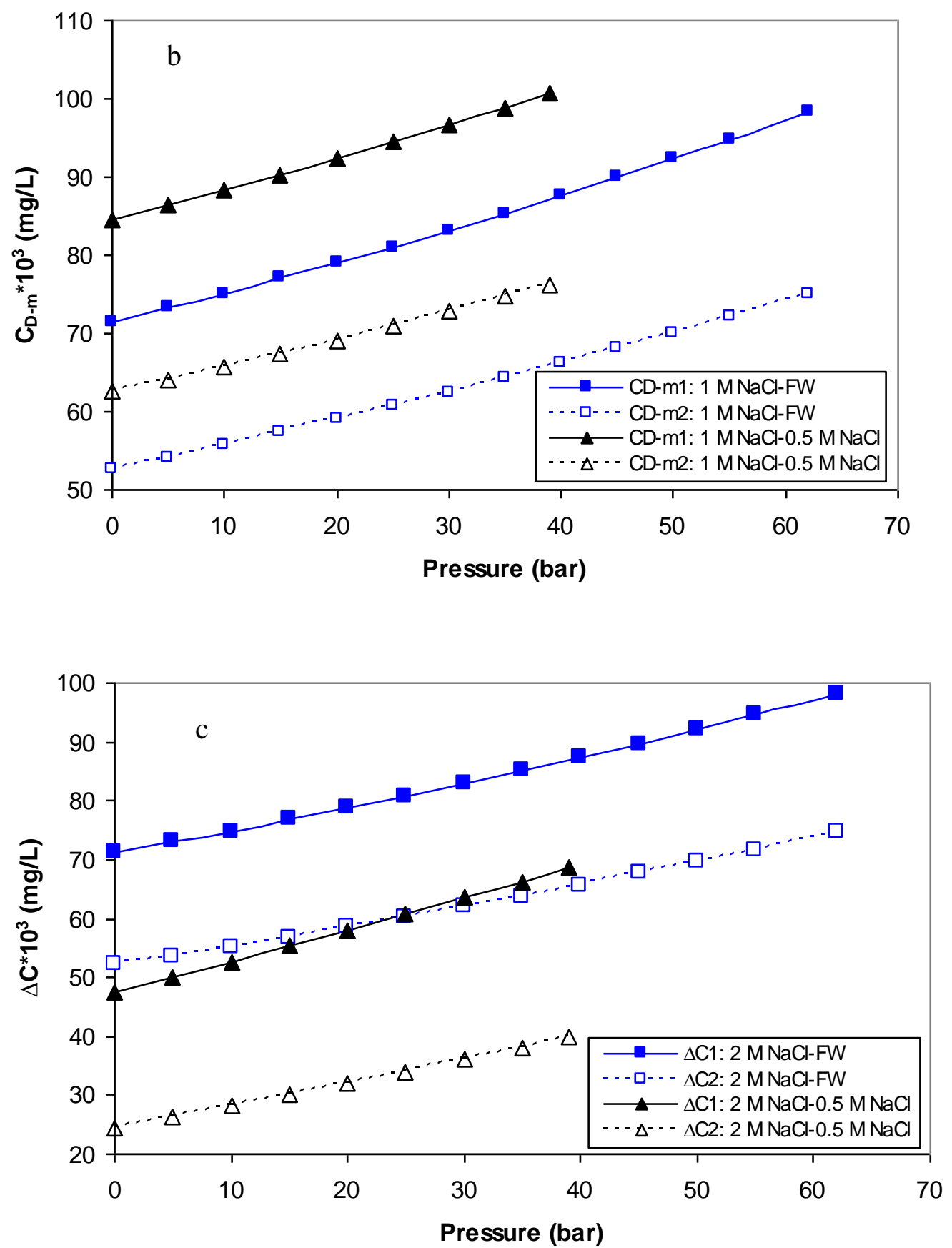

Figure 7: Reverse salt diffusion and draw solution concentration at the membrane wall at different feed pressures, (a) reverse salt diffusion (b) draw solution concentration at the membrane surface (c) feed solution concentration at the membrane surface, testing condition: $Q_{\text {f-in }} / Q_{d s-i n}$ was 1 and 1.2 in stage 1 and 2 respectively for $2 \mathrm{M}-2 \mathrm{~g} / \mathrm{L}$ salinity gradient resource and 1 and 3 in stage 1 and 2 respectively for $2 \mathrm{M}-0.5 \mathrm{M}$ salinity gradient resource. 
As shown in Figure $7 a, J_{s-r 1}$ was always higher than $J_{s-r 2}$ because of the higher $C_{D-m 1}$. For example, with a $2 \mathrm{M} \mathrm{NaCl}-\mathrm{FW}$ osmotic gradient resource and 0 bar feed pressure, $J_{s-r 1}$ and $J_{s-}$ ${ }_{r 2}$ were 0.549 and $0.343 \mathrm{~mol} / \mathrm{m}^{2} \mathrm{~h}$, respectively. The corresponding values of $C_{D-m 1}$ and $C_{D-m 2}$ were 71 and $52.6 \mathrm{~g} / \mathrm{L}$, respectively. Similarly, with a $2 \mathrm{M}-0.5 \mathrm{M} \mathrm{NaCl}$ osmotic gradient resource and 0 bar feed pressure, $J_{s-r 1}$ and $J_{s-r 2}$ were 0.322 and $0.166 \mathrm{~mol} / \mathrm{m}^{2} \mathrm{~h}$, respectively; and the corresponding values of $C_{D-m 1}$ and $C_{D-m 2}$ were 84 and $62.5 \mathrm{~g} / \mathrm{L}$. Despite the higher $C_{D-}$ $m 1$ and $C_{D-m 2}$ for $2 \mathrm{M}-0.5 \mathrm{M} \mathrm{NaCl}$ salinity gradient, $J_{s-r 1}$ and $J_{s-r 2}$ were higher for $2 \mathrm{M} \mathrm{NaCl}-\mathrm{FW}$ salinity gradient. Practically, salt diffusion across the membrane is affected by the concentration difference. Therefore, the concentration difference across the membrane in stage one and two, $\Delta \mathrm{C}_{1}$ and $\Delta \mathrm{C}_{2}$ (g/L) was calculated for the salinity gradients under investigation here [Figure7c]. $\Delta C$ was calculated as the difference between $C_{D-m}$ and $C_{F-m}$ and it was indicative of the salinity gradient across the PRO membrane. The higher $\Delta C$ was, the higher the salt diffusion across the membrane. The simulation results showed that $\Delta C$ was higher with a $2 \mathrm{M} \mathrm{NaCl}-\mathrm{FW}$ rather than with a $2 \mathrm{M}-0.5 \mathrm{M} \mathrm{NaCl}$ salinity gradient resource. At 0 bar hydraulic pressure, $\Delta \mathrm{C}_{1}$ was 71.2 and $47.5 \mathrm{~g} / \mathrm{L}$ for $2 \mathrm{M} \mathrm{NaCl}-\mathrm{FW}$ and $2 \mathrm{M}$ $0.5 \mathrm{M} \mathrm{NaCl}$, respectively; whereas $\Delta \mathrm{C}_{2}$ was 52 and $24 \mathrm{~g} / \mathrm{L}$, respectively. This result explained why $J_{s-r 1}$ and $J_{s-r 2}$ were higher with a $2 \mathrm{M} \mathrm{NaCl}-\mathrm{FW}$ than with a $2 \mathrm{M}-0.5 \mathrm{M} \mathrm{NaCl}$ salinity gradient. It is mentioned here that higher reverse salt diffusion increases the operation cost of the PRO process and has adverse impact on the process performance.

\subsection{Open-loop PRO dual stage PRO power plant}

A Dead Sea-seawater salinity gradient resource was evaluated for power generation by the dual stage PRO process. Two seawater concentrations were investigated here, i.e. 35 and $40 \mathrm{~g} / \mathrm{L}$, to simulate the salinity of Mediterranean Sea and Red Sea water, respectively. The impact of feed salinity and hydraulic pressure on the PRO process performance is shown in Figure 8. At comparable hydraulic pressures, first and second stage power densities, $W_{1}$ and $W_{2}$ respectively, increased with increasing hydraulic pressure and they were higher at $35 \mathrm{~g} / \mathrm{L}$ than at $40 \mathrm{~g} / \mathrm{L}$ seawater salinity [Figure $8 \mathrm{a}$ ]. 

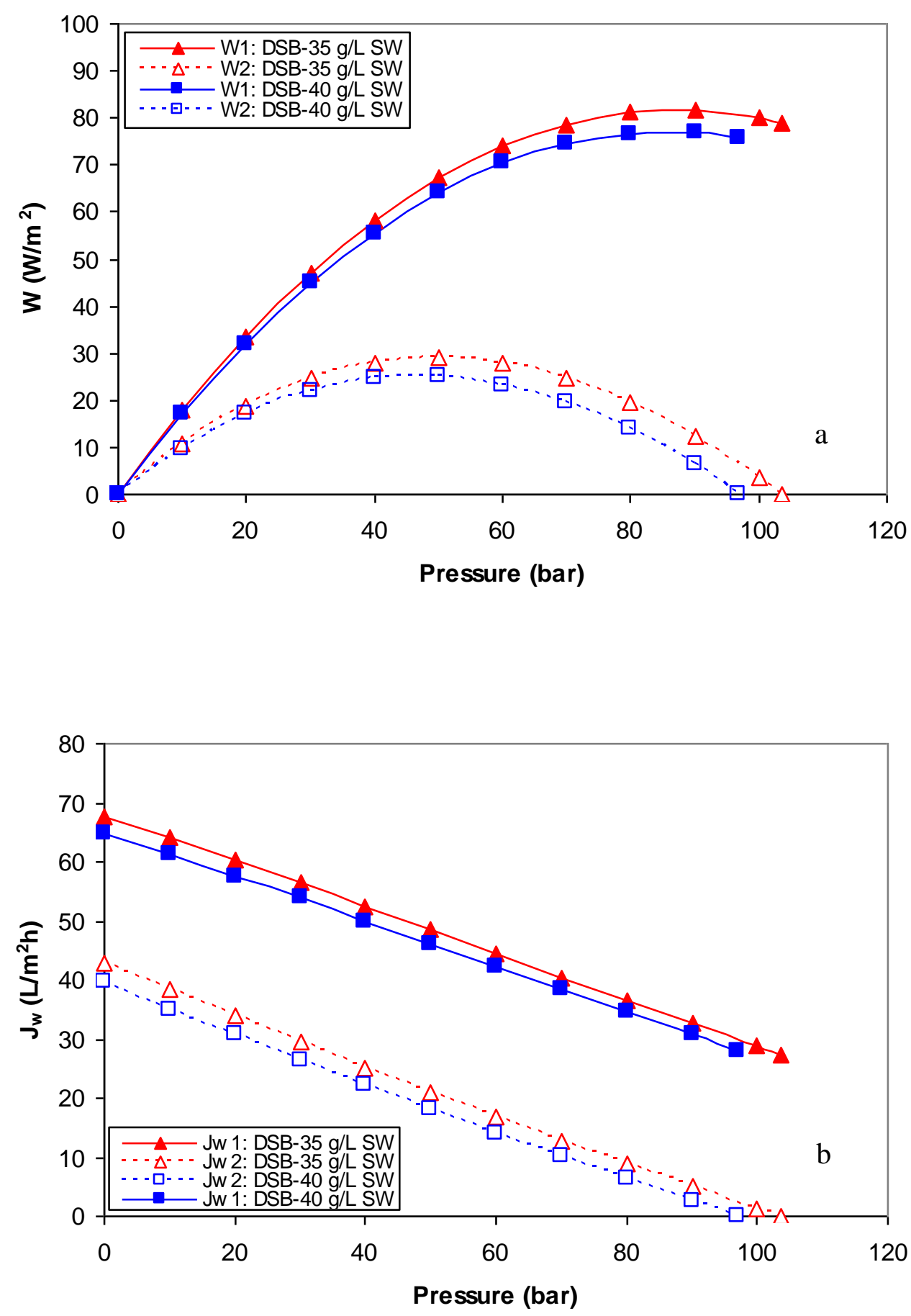


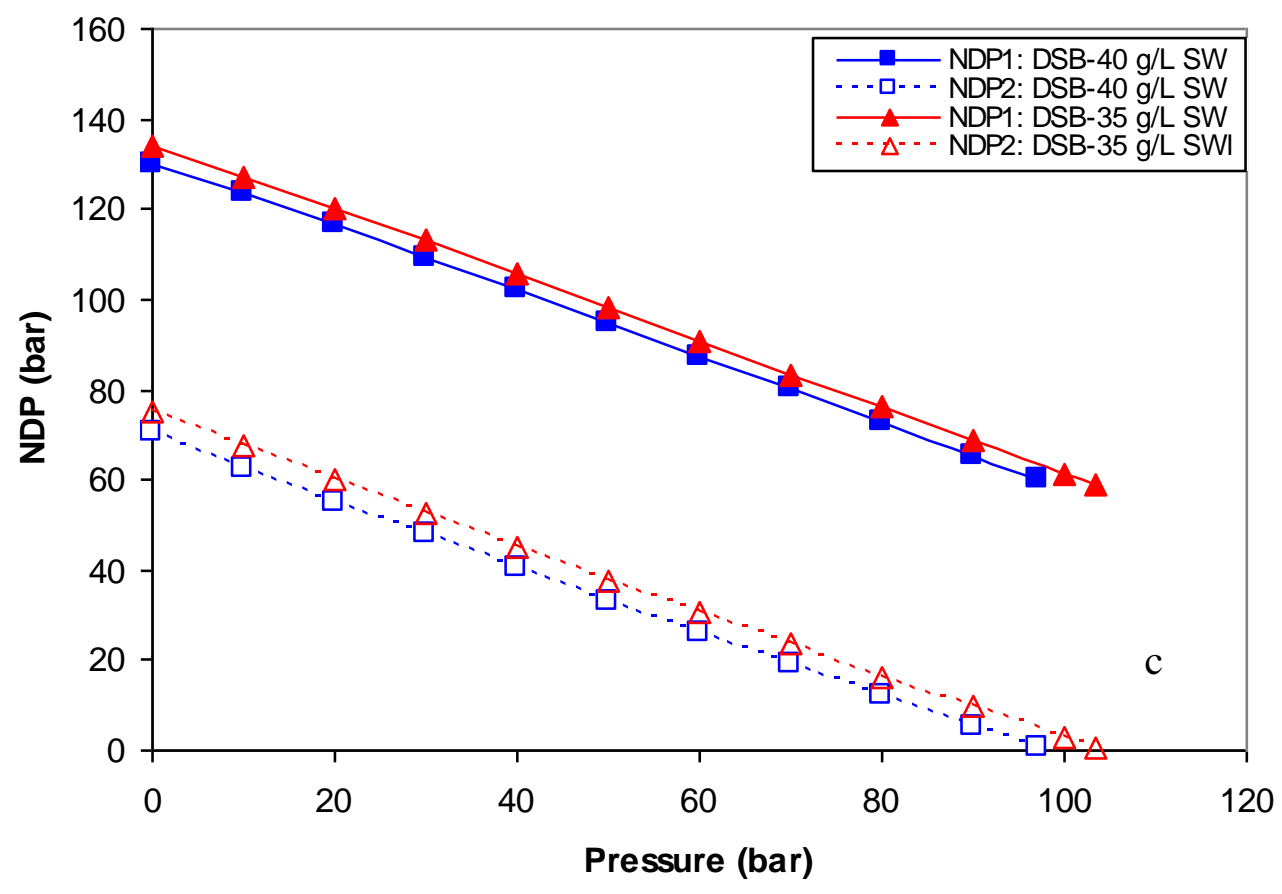

Figure 8: Impact of feed salinity and hydraulic pressure on the dual stage PRO process a) impact on power density b) membrane flux c) NDP

It is suggested that this behaviour could be attributed to the higher NDP which resulted in a higher membrane flux at $35 \mathrm{~g} / \mathrm{L}$ seawater salinity [Figures $8 \mathrm{~b}$ and $8 \mathrm{c}$ ]. $W_{1}$ reached a maximum amount of 44 and $40.8 \mathrm{~W} / \mathrm{m}^{2}$ for 35 and $40 \mathrm{~g} / \mathrm{L}$ seawater salinity, respectively. In the second stage, $W_{2}$ reached a maximum value of 20 and $17 \mathrm{~W} / \mathrm{m}^{2}$ for 35 and $40 \mathrm{~g} / \mathrm{L}$ seawater salinity, respectively. This data revealed 7 and $15 \%$ decrease in $W_{1}$ and $W_{2}$ respectively, due to a feed salinity increase from 35 to $40 \mathrm{~g} / \mathrm{L}$. $J_{w}$, in general, decreased with increasing feed salinity due to the lower NDP across the membrane. The simulation results showed that the membrane flux of stage one and two, $J_{w 1}$ and $J_{w 2}$, was higher at $35 \mathrm{~g} / \mathrm{L}$ than $40 \mathrm{~g} / \mathrm{L}$ feed salinity (Figure 8b]. As shown in Figure 8c, the lower $J_{w 1}$ and $J_{w 2}$ at $35 \mathrm{~g} / \mathrm{L}$ feed salinity was due to the lower NDP in stage one and two, NDP 1 and NDP 2 respectively. It is noted that $\mathrm{W}_{2}$ reached a maximum value at $\Delta P_{2} \approx \Delta \pi_{2} / 3$; this ratio was applied onto 35 $\mathrm{g} / \mathrm{L}$ and $40 \mathrm{~g} / \mathrm{L}$ feed salinities. At $\Delta P_{2} \approx \Delta \pi_{2} / 3, \mathrm{~W}_{\max 2}$ was approximately 32 and $37 \%$ of $\mathrm{W}_{\max 1}$ for 40 and $35 \mathrm{~g} / \mathrm{L}$ feed salinities, respectively. These results, however, were based on the hypothesis that no pressure losses were incurred in the first stage of the PRO process. 
Similar to closed-loop dual stage PRO process, reverse salt diffusion was evaluated at 35 and $40 \mathrm{~g} / \mathrm{L}$ feed solutions using Dead Sea brine draw solution in the salinity gradient. The simulation results show that $J_{s-r 1}$ and $J_{s-r 2}$ increased with increasing the hydraulic pressure. Furthermore, $J_{s-r 1}$ and $J_{s-r 2}$ were higher at $35 \mathrm{~g} / \mathrm{L}$ than at $40 \mathrm{~g} / \mathrm{L}$ feed solution (figure 9a) despite $C_{D-m 1}$ and $C_{D-m 2}$ were higher at $40 \mathrm{~g} / \mathrm{L}$ feed solution (figure $9 \mathrm{~b}$ ). This was due to the higher reverse salt diffusion of stage one and two, $\Delta C_{1}$ and $\Delta C_{2}(g / L)$ respectively, at $35 \mathrm{~g} / \mathrm{L}$ feed solution. For example, at 40 bar hydraulic pressure, $\Delta C_{1}$ and $\Delta C_{2}$ were 53.7 and $17.3 \mathrm{~g} / \mathrm{L}$ respectively for $40 \mathrm{~g} / \mathrm{L}$ feed solution and 59 and $27.3 \mathrm{~g} / \mathrm{L}$ respectively for $35 \mathrm{~g} / \mathrm{L}$ (figure 9c). obviously, the results show that increasing $\Delta C$ results in a higher reverse salt diffusion from the draw to the feed solution knowing that $\Delta C=C_{D-m}-C_{F-m}$.

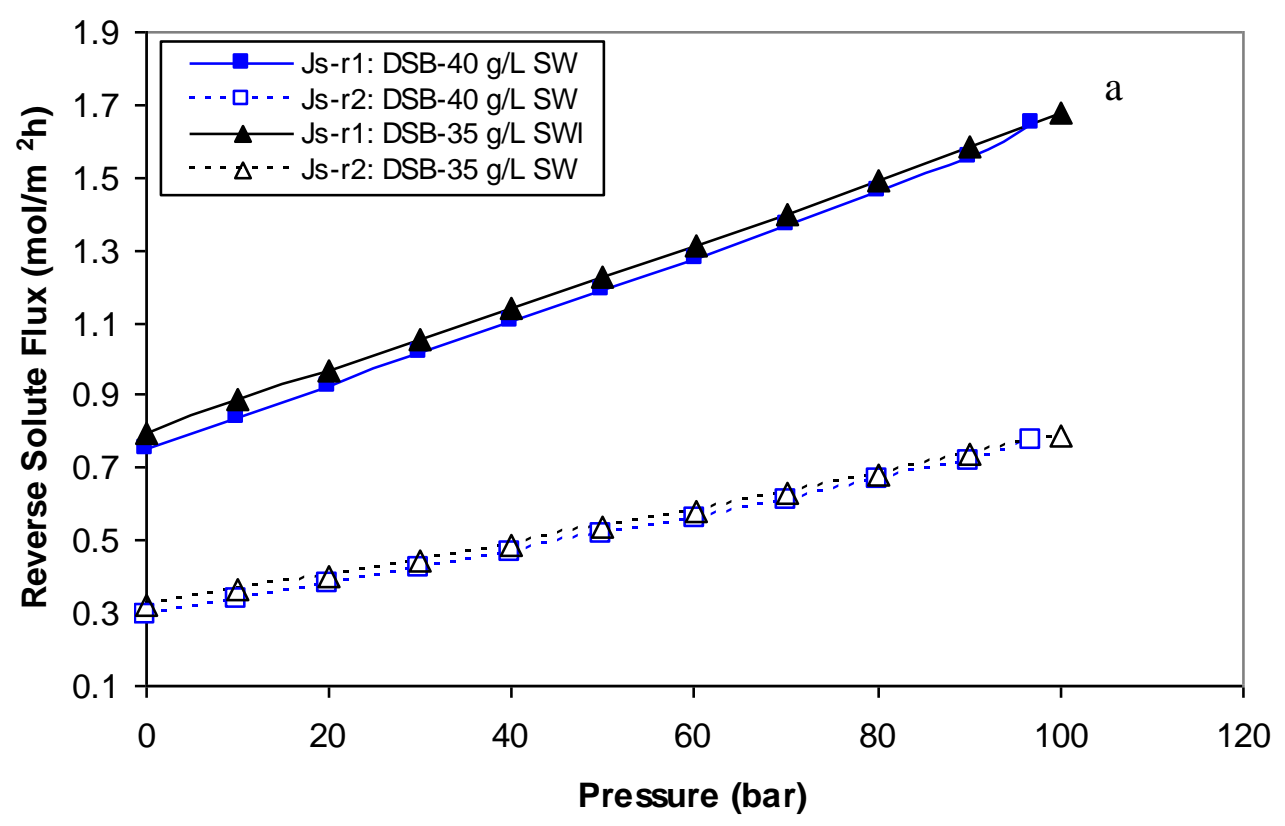



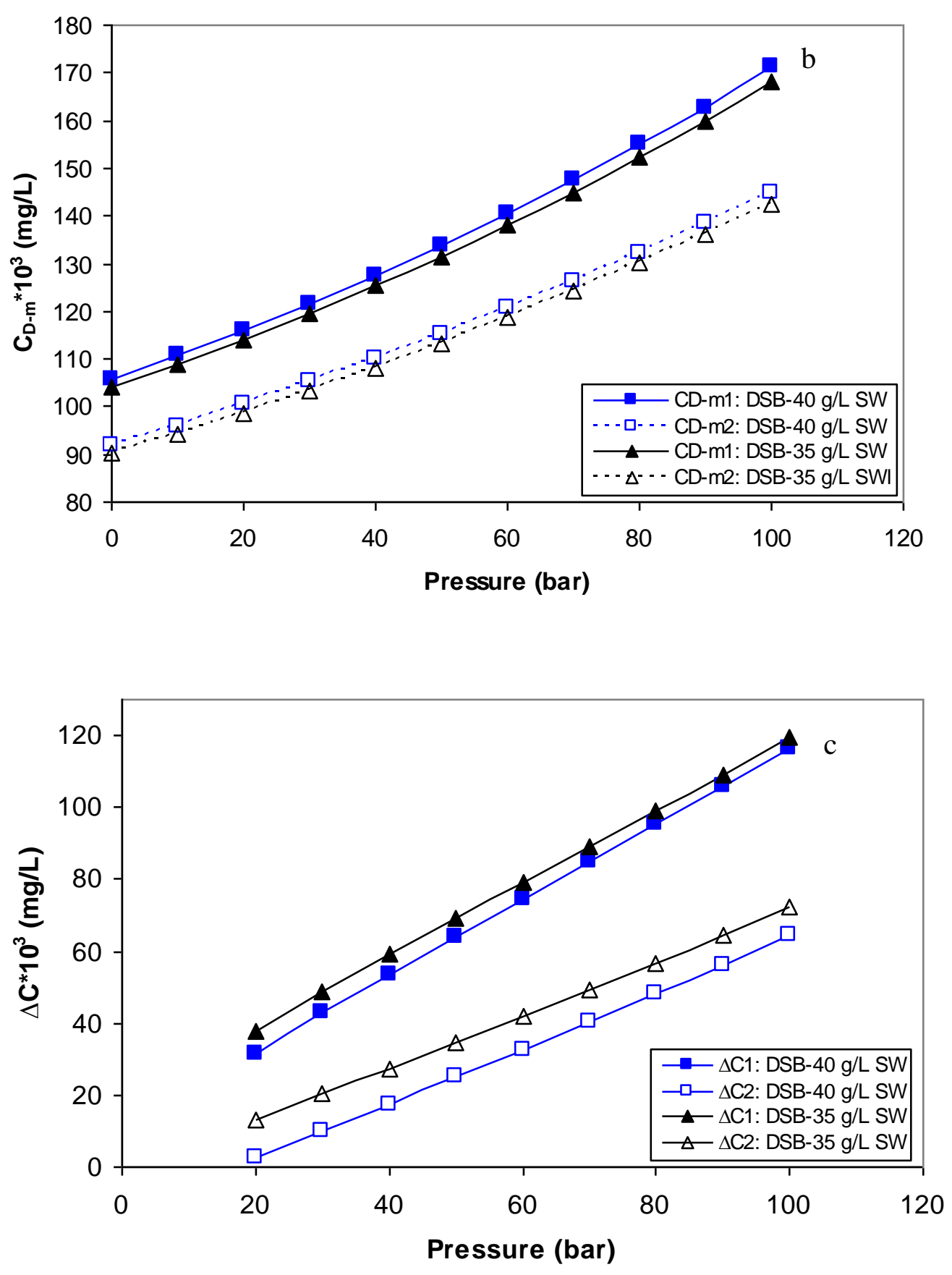

Figure 9: Impact of hydraulic pressure on a) reverse salt diffusion in PRO membrane b) concentration of draw solution on the membrane surface c) on concentration gradient across the membrane, draw solution Dead Sea brine paired with $35 \mathrm{~g} / \mathrm{L}$ and $40 \mathrm{~g} / \mathrm{L}$ seawater feed solution

In the dual stage PRO process, maximum power density in stage one, $W_{\max 1}$, occurred at $\Delta P=\Delta \pi / 2$ while maximum power density in stage $2, W_{\max 2 \text {, occurred at }}$ 
$\Delta P_{2} \approx \Delta \pi_{2} / 3$ [Figures 5a and 8 a]. As a result, the maximum net power generation, $P_{w n}$, occurred at $\Delta P$ different to that required for $W_{\max 1}$, i.e. $\Delta P=\Delta \pi / 2 . P_{w n}$ was calculated from the Equation 16:

Equation 16

$$
P_{w n}=P_{w-d u a l}-P_{\text {consump }}
$$

$P_{w-d u a l}$ and $P_{\text {consump }}$ represent power generation and consumption respectively in the dual stage PRO process. For the salinity gradient resource $2 \mathrm{M} \mathrm{NaCl}-\mathrm{FW}$, simulation results show that maximum net power generation $\left(0.25 \mathrm{kWh} / \mathrm{m}^{3}\right)$ occurred at $\Delta P$ equal to 35 bar [Figure 10a]. This $\Delta P$ is approximately 10 bar lower than the $\Delta P$ required for power density to reach the maximum amount, $W_{\max 1}$. This finding held true for other salinity gradient resources, with results indicating that maximum power generation occurred at $\Delta P$ less than that required for power density to reach $W_{\max 1}$ [Figures $10 \mathrm{a}$ and $10 \mathrm{~b}$ ]. These results have implications, in practical terms, on the operating parameters of the dual stage PRO process. Typically, the recommended operating hydraulic pressure in a single stage PRO process should be equal to $\Delta \pi / 2$. However, the performance of dual stage PRO process will not be optimal at $\Delta P=\Delta \pi / 2$ as have been shown in previous studies [19]. Thus, the optimum operating pressure value needs to be experimentally optimized in order to maximize the power generation from the dual stage PRO process. One of issues which affects the performance of PRO process, in general, is the relatively high power consumption in stage one of the dual stage PRO process, which requires two pumps for the feed and draw solutions.

The results also show that at $\Delta P$ between 0 and 5 bar and $2 \mathrm{M} \mathrm{NaCl}$ draw solution concentration, the net power generation was less than the gross power consumption [Figure 10a]. This was particularly obvious for $2 \mathrm{M}-0.5 \mathrm{M} \mathrm{NaCl}$ salinity gradient resources, but to a less extent for $2 \mathrm{M} \mathrm{NaCl}-\mathrm{FW}$ salinity gradient resource. In the latter case, the net power generation was a negative value at a hydraulic pressure $<5$ bar then increased to $0.01 \mathrm{kWh} / \mathrm{m}^{3}$ at 5 bar. The underperformance of $2 \mathrm{M}-0.5 \mathrm{M} \mathrm{NaCl}$ salinity gradient resource was mainly due to stage one [Figure 10c] where the net power generation in stage one was lower than the power consumption at feed pressures between 0 and 40 bar. Whilst power 
consumption in stage two was lower than power generation, which resulted in a positive net power generation.
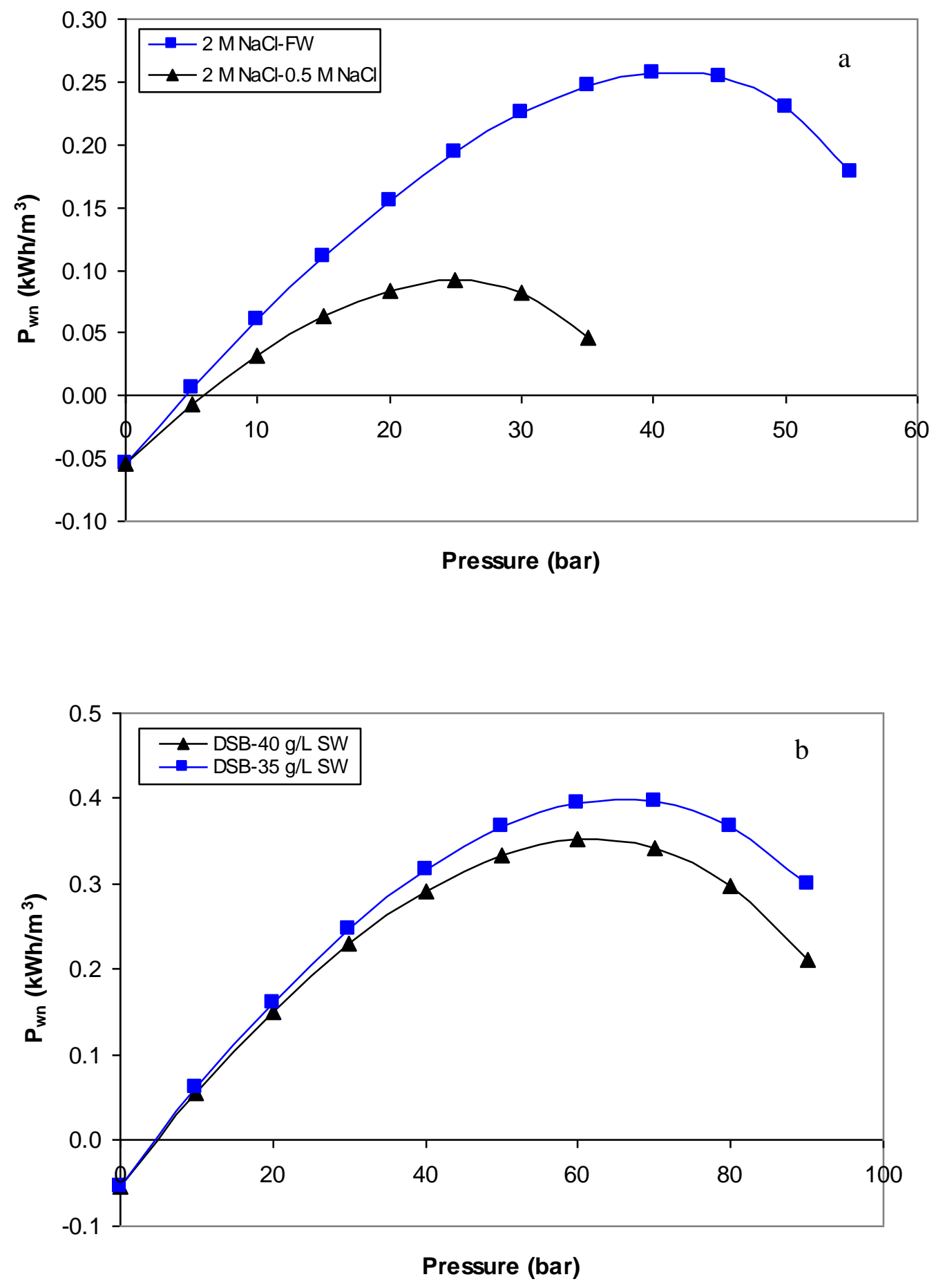


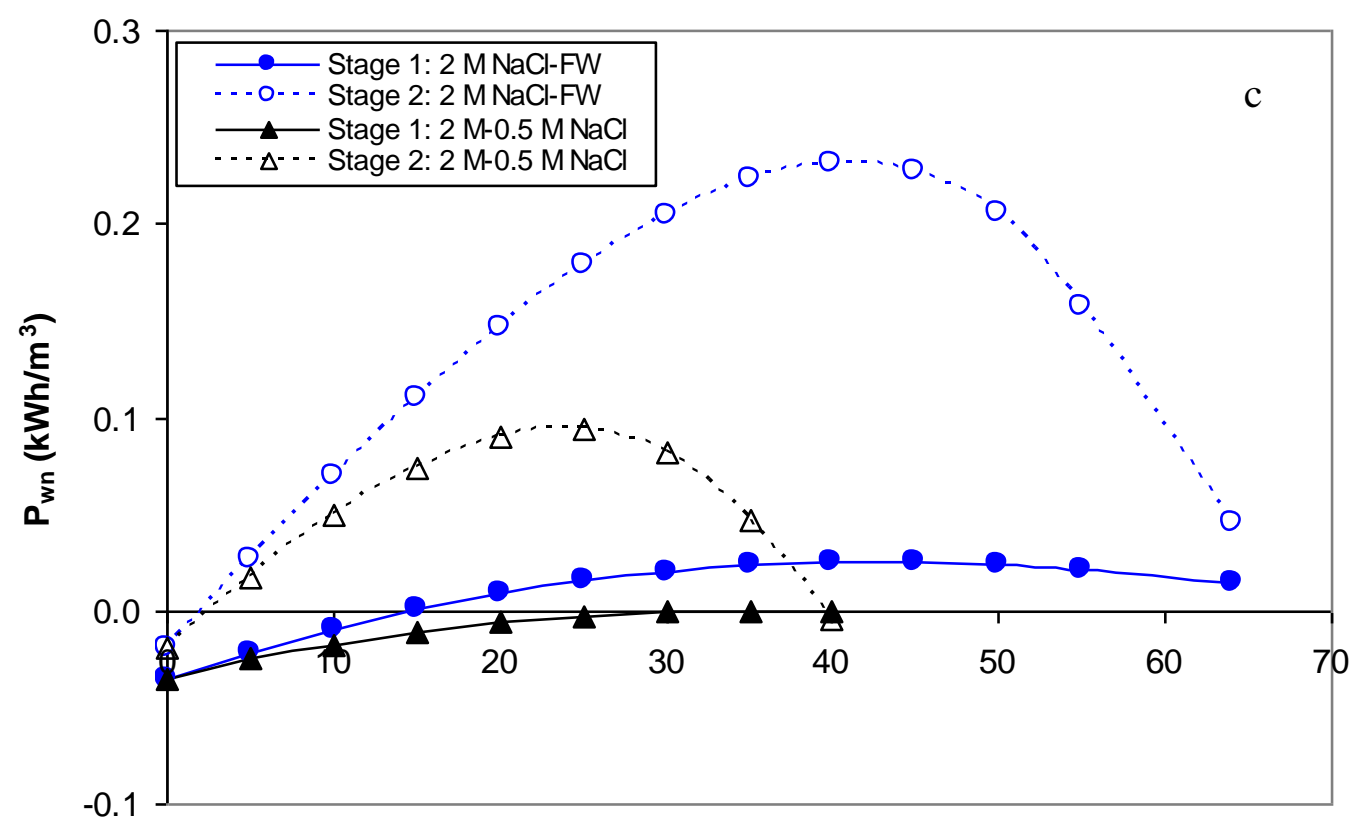

Hydraulic Pressure (bar)

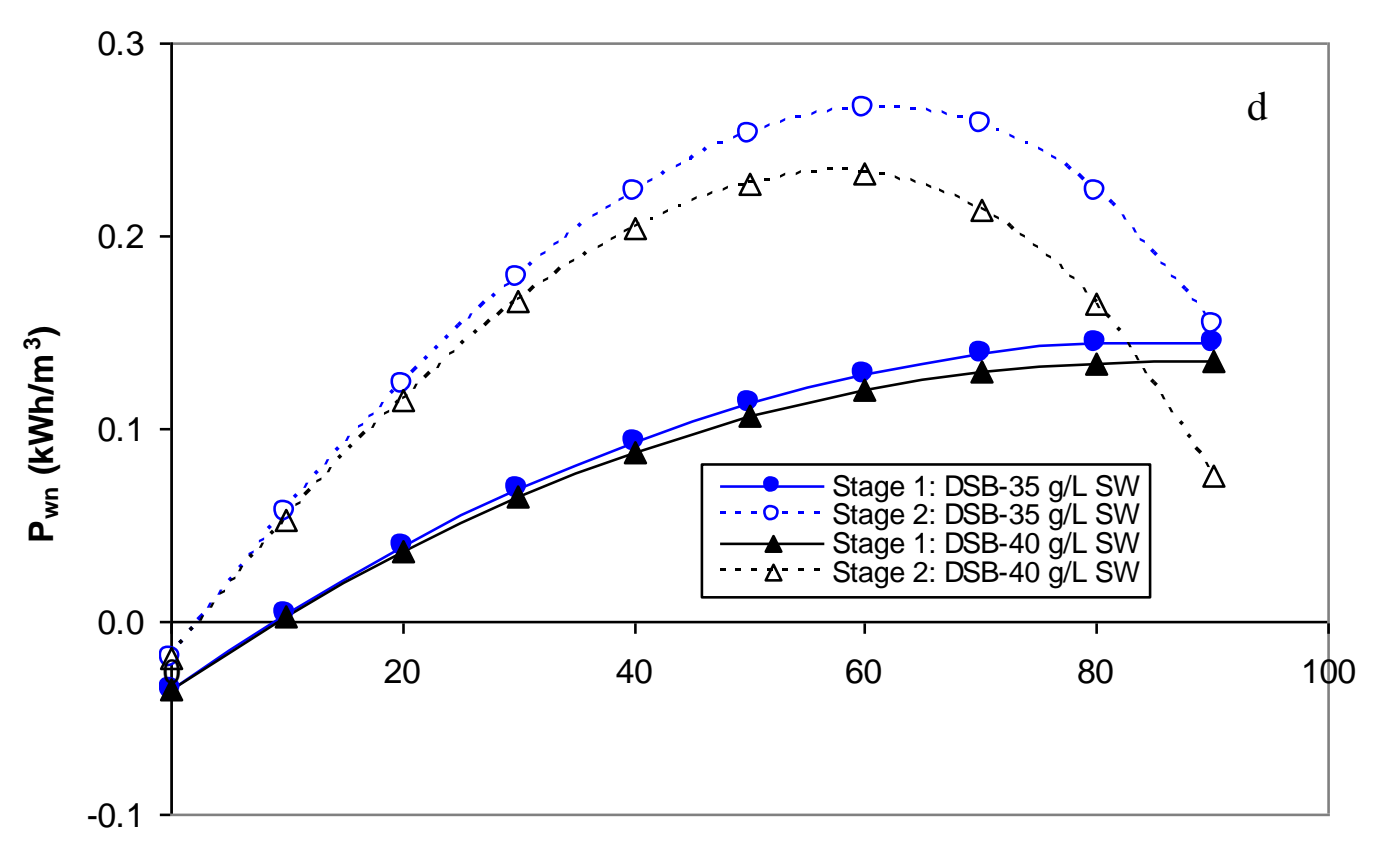

Hydraulic Pressure (bar)

Figure 10: Power generation in dual stage PRO process at different hydraulic pressures a) total net power generation at $2 \mathrm{M} \mathrm{NaCl}-\mathrm{FW}$ and $2 \mathrm{M}-0.5 \mathrm{M} \mathrm{NaCl}$ salinity gradient resources

b) total net power generation at DSB-35 g/L SW and DSB-40 g/L SW salinity gradient resources c) net power generation in stage one and two at $2 \mathrm{M} \mathrm{NaCl}-\mathrm{FW}$ and $2 \mathrm{M} \mathrm{NaCl}-0.5$ 
$\mathrm{M} \mathrm{NaCl}$ salinity gradient resources d) net power generation in stage one and two at DSB-35 g/L SW and DSB-40 g/L SW salinity gradient resources

The performance of stage one and stage two of the dual stage PRO process improved when $2 \mathrm{M} \mathrm{NaCl}$ was paired with fresh water. However, a higher performance of stage one, in particular, and two, in general, occurred when Dead Sea-35 g/L seawater and Dead Sea-40 $\mathrm{g} / \mathrm{L}$ seawater were the salinity gradient resources [Figure $10 \mathrm{~d}$ ]. At these latter salinity gradients, power generation in stage one was less than power consumption only at feed pressures less than 10 bar. As such, the performance of a dual stage PRO process can be highly improved through optimizing the salinity gradient resource and hydraulic pressure. The combination of using a sufficiently high salinity gradient resource and hydraulic pressure across the membrane will considerably enhance the process performance. Furthermore, using very low or high hydraulic pressures may result in an unsatisfactory performance in one of both stages of the dual stage PRO process.

Typically, power consumption in the PRO process was a small percentage but it was slightly higher than that in the conventional PRO process due to the extra feed pump in stage two. Total power generation and consumption in the dual stage PRO process is shown in Table 2. Using Dead Sea as draw solution resulted in doubling the total power generation compared to $2 \mathrm{M} \mathrm{NaCl}$. The breakdown percentage of power generation and consumption in the dual stage PRO process is shown in Figure 11. The percentage of power consumption increased when the hydraulic pressure deviated from an optimum value which was slightly lower than $\Delta \pi / 2$ and/or when the osmotic pressure gradient was moderately low. For example, at 2 $\mathrm{M} \mathrm{NaCl}-\mathrm{FW}$ salinity gradient and 20 bar hydraulic pressure, power consumption in stage one and two were $17 \%$ and $9 \%$ respectively, of the total power generation; whereas the net power generation was $74 \%$ of the total power generation [Figure 11a]. However, at 20 bar hydraulic pressure, the percentage of power consumption in stage one and two increased to $25 \%$ and $14 \%$, respectively; while the net power generation was $61 \%$ of the total power generation when the feed salinity increased to $0.5 \mathrm{M} \mathrm{NaCl}$ [Figure 11b]. The higher power consumption for $0.5 \mathrm{M}$ feed solution was mainly due to the lower NDP which affected water flux across the membrane [Figure 6]. Using Dead Sea-35 g/L seawater and Dead Sea-40 g/L seawater salinity gradients increased the performance of the dual stage PRO process due to 
the higher NDP and hence water flux across the membrane [Figures $11 \mathrm{c}$ and $11 \mathrm{~d}$ ]. At 20 bar hydraulic pressure and with a Dead Sea-35 g/L seawater salinity gradient, the percentage of power consumption in stage one and two was $16 \%$ and $9 \%$, respectively; while the net power generation was $75 \%$ of the total power generation [Figure 11c]. The percentage of net power generation slightly decreased to $74 \%$ when the feed salinity increased to $40 \mathrm{~g} / \mathrm{L}$ [Figure 11d].

The results demonstrated that dual stage performance can be significantly improved by increasing the osmotic pressure of draw solution. Figure 11 also showed the impact of hydraulic pressure on the process performance. Indeed, hydraulic pressure must be optimized in order to increase the net power generation from the salinity gradient in the dual stage PRO process [Figure 10]. This issue should be considered upon the design of high performance dual stage PRO process.

Table 2: Net power generation and power consumption in dual stage PRO process for different salinity gradients and feed pressures

\begin{tabular}{|c|c|c|c|c|c|c|c|c|c|}
\hline \multirow{2}{*}{$\begin{array}{l}\text { Pressure } \\
\text { (bar) }\end{array}$} & \multicolumn{2}{|c|}{$2 \mathrm{M} \mathrm{NaCl}-\mathrm{FW}$} & \multicolumn{2}{|c|}{$2 \mathrm{M}-0.5 \mathrm{M} \mathrm{NaCl}$} & \multirow{2}{*}{$\begin{array}{l}\text { Pressure } \\
\text { (bar) }\end{array}$} & \multicolumn{2}{|c|}{ DS-35 g/L SW } & \multicolumn{2}{|c|}{ DS-40 g/L SW } \\
\hline & $\begin{array}{c}\mathrm{P}_{\mathrm{wn}-\mathrm{t}}{ }^{*} \\
\mathrm{kWh} / \mathrm{m}^{3}\end{array}$ & $\begin{array}{l}\mathrm{P}_{\mathrm{wc}-\mathrm{t}}{ }^{* *} \\
\mathrm{kWh} / \mathrm{m}^{3}\end{array}$ & $\begin{array}{c}\mathrm{P}_{\mathrm{wn}-\mathrm{t}}{ }^{*} \\
\mathrm{kWh} / \mathrm{m}^{3}\end{array}$ & $\begin{array}{l}\mathrm{P}_{\mathrm{wc}-\mathrm{t}}{ }^{* *} \\
\mathrm{kWh} / \mathrm{m}^{3}\end{array}$ & & $\begin{array}{l}\mathrm{P}_{\mathrm{wn}-\mathrm{t}}{ }^{*} \\
\mathrm{kWh} / \mathrm{m}^{3}\end{array}$ & $\begin{array}{l}\mathrm{P}_{\mathrm{wc}-\mathrm{t}}{ }^{* *} \\
\mathrm{kWh} / \mathrm{m}^{3}\end{array}$ & $\begin{array}{l}\mathrm{P}_{\mathrm{wn}-\mathrm{t}}{ }^{*} \\
\mathrm{kWh} / \mathrm{m}^{3}\end{array}$ & $\begin{array}{l}\mathrm{P}_{\mathrm{wc}-\mathrm{t}}{ }^{* *} \\
\mathrm{kWh} / \mathrm{m}^{3}\end{array}$ \\
\hline 0 & 0.00 & 0.05 & 0.00 & 0.05 & 0 & 0.00 & 0.05 & 0.00 & 0.05 \\
\hline 5 & 0.06 & 0.05 & 0.05 & 0.05 & 10 & 0.11 & 0.05 & 0.11 & 0.05 \\
\hline 10 & 0.11 & 0.05 & 0.09 & 0.05 & 20 & 0.22 & 0.05 & 0.20 & 0.05 \\
\hline 15 & 0.16 & 0.05 & 0.12 & 0.05 & 30 & 0.30 & 0.05 & 0.28 & 0.05 \\
\hline 20 & 0.21 & 0.05 & 0.14 & 0.05 & 40 & 0.37 & 0.05 & 0.35 & 0.05 \\
\hline 25 & 0.25 & 0.05 & 0.15 & 0.05 & 50 & 0.42 & 0.05 & 0.39 & 0.05 \\
\hline 30 & 0.28 & 0.05 & 0.14 & 0.05 & 60 & 0.45 & 0.05 & 0.41 & 0.05 \\
\hline 35 & 0.30 & 0.05 & 0.10 & 0.05 & 70 & 0.45 & 0.05 & 0.40 & 0.05 \\
\hline 40 & 0.31 & 0.05 & 0.05 & 0.05 & 80 & 0.42 & 0.05 & 0.35 & 0.05 \\
\hline 45 & 0.31 & 0.05 & & & 90 & 0.35 & 0.05 & 0.26 & 0.05 \\
\hline 50 & 0.28 & 0.05 & & & & & & & \\
\hline 55 & 0.23 & 0.05 & & & & & & & \\
\hline
\end{tabular}

*total power generation

$* *$ total power consumption 

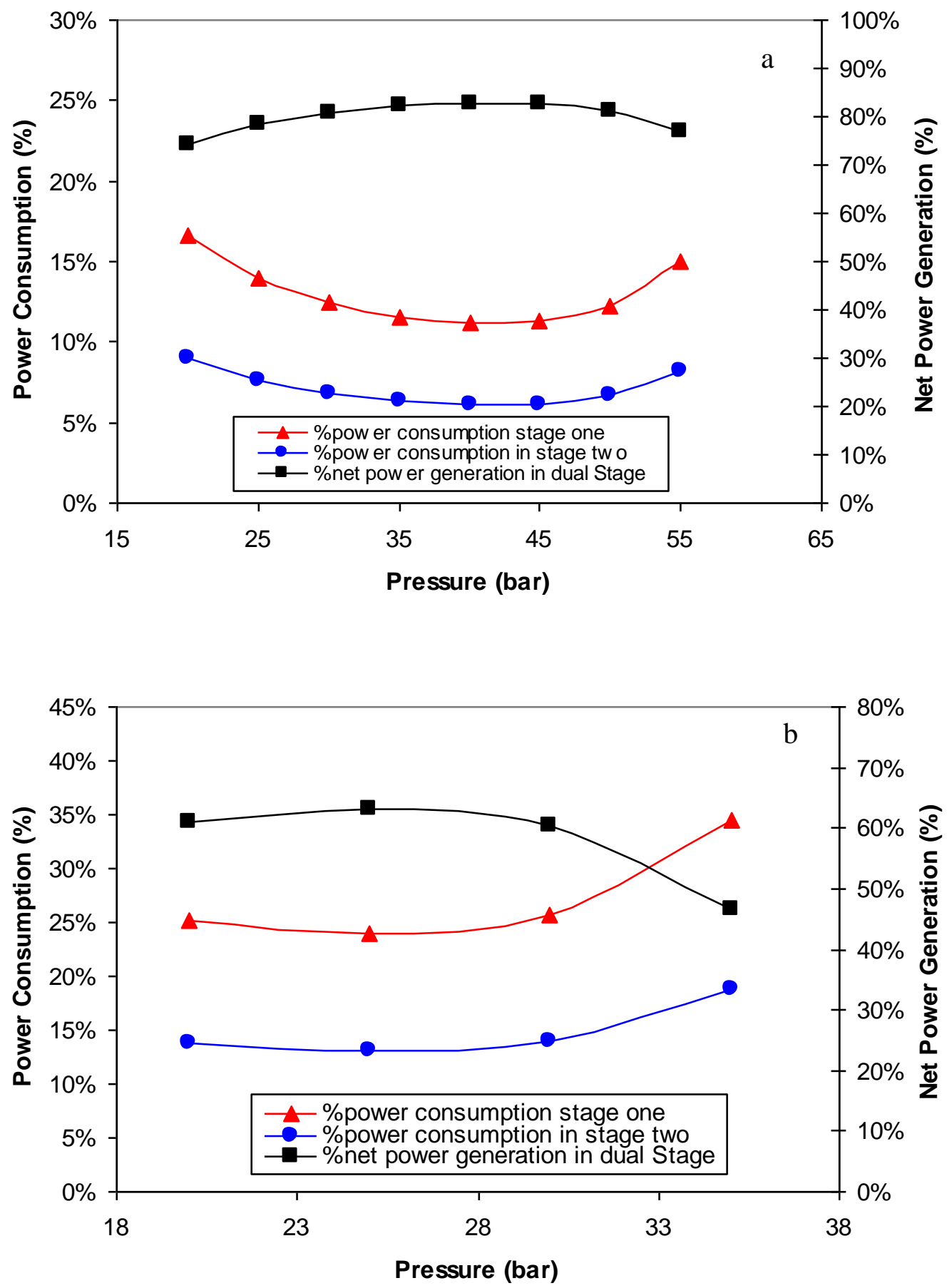


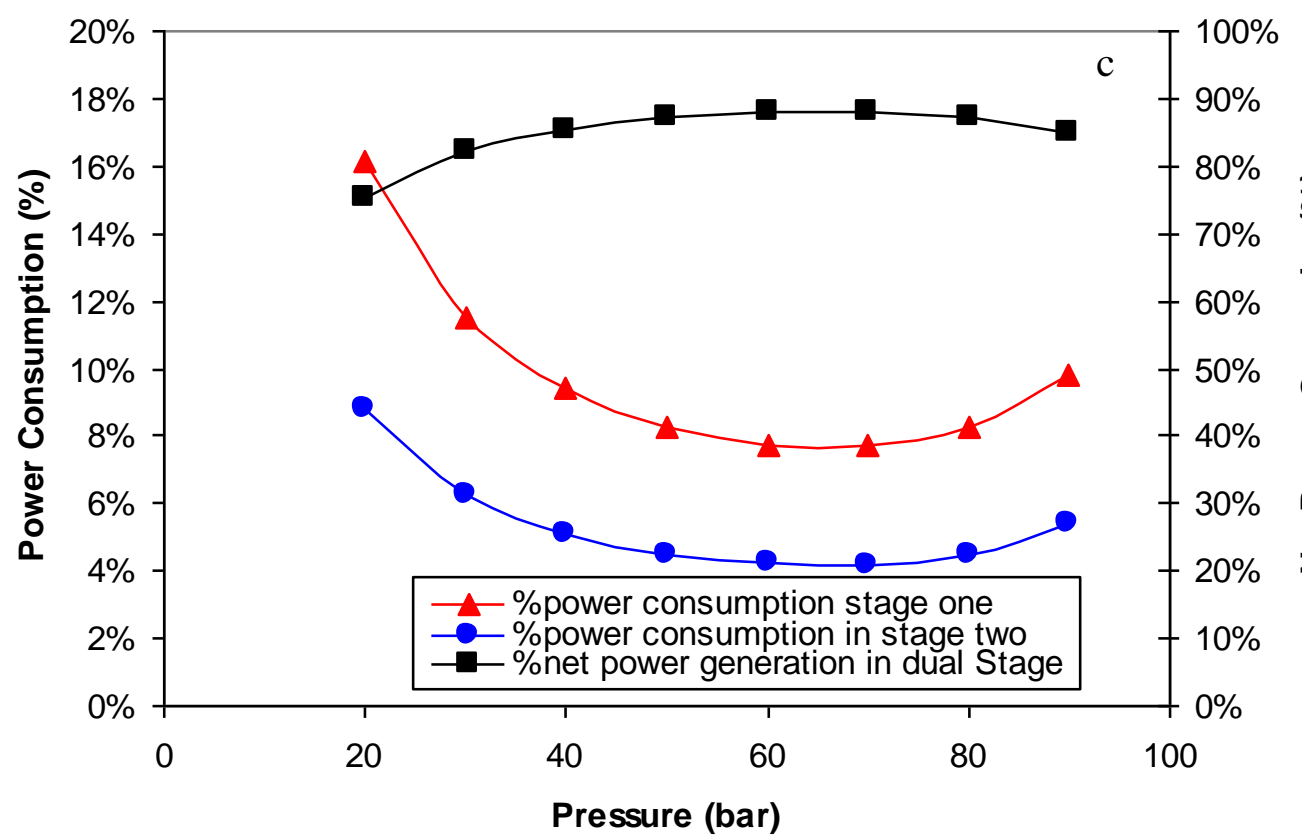

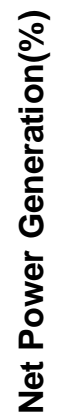

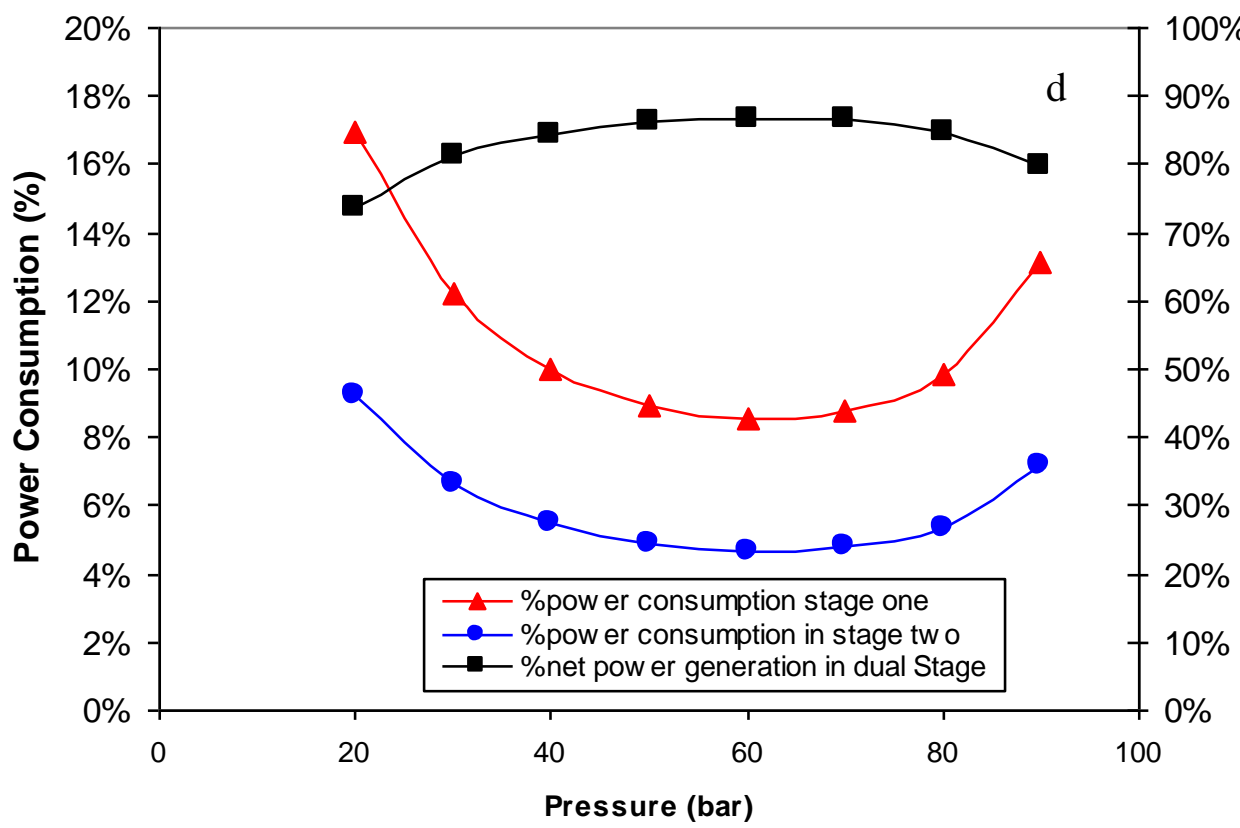

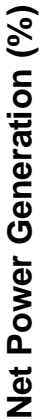

Figure 11: Net power consumption and generation in the dual stage PRO process a) $2 \mathrm{M}$ $\mathrm{NaCl}-\mathrm{FW}$ salinity gradient resource b) $2 \mathrm{M}-0.5 \mathrm{M} \mathrm{NaCl}$ salinity gradient resource c) DSB-35 $\mathrm{g} / \mathrm{L}$ seawater salinity gradient resource d) DSB-40 g/L seawater salinity gradient resource 


\section{Conclusions}

Power generation from a dual stage PRO process was evaluated for a number of salinity gradients. The performance of dual stage PRO process was highly dependent on the salinity gradient resources and applied hydraulic pressure. Reverse salt diffusion was estimated due to its adverse impact on the process performance. For a given salinity gradient resource, reverse salt diffusion increased with decreasing salinity of the feed solution. Reverse salt diffusion was mainly controlled by the concentration difference across the membrane, $\Delta C$, instead of the concentration of draw solution on the membrane surface $C_{D-m}$. Furthermore, this study found that net power generation was a more reliable indicator than power density to estimate the performance of dual stage PRO process. Power consumption in the dual stage PRO process was mainly due to first stage feed pumping. In general, power generation in the dual stage PRO process was higher than that in the conventional PRO process by an amount equal to that generated in stage two for the dual stage PRO. However, dual stage PRO process operates better with a higher salinity gradient resource. More work is required in the development of a simple approach to estimate concentration polarization in full scale PRO membrane. 


\section{References}

[1] S.E. Skilhagen, J.E. Dugstad, R.J. Aaberg, Osmotic power - power production based on the osmotic pressure difference between waters with varying salt gradients, Desalination, 220 (2008) 476-482.

[2] R.J. Aaberg, Osmotic Power: A new and powerful renewable energy source?, Refocus, 4 (2003) 48-50.

[3] K. Saito, M. Irie, S. Zaitsu, H. Sakai, H. Hayashi, A. Tanioka, Power generation with salinity gradient by pressure retarded osmosis using concentrated brine from SWRO system and treated sewage as pure water, Desalination and Water Treatment, 41 (2012) 114-121.

[4] S. Patel, Norway inaugurates osmotic power plant, Power, 154 (2010).

[5] A.O. Sharif, A.A. Merdaw, M. Aryafar, P. Nicoll, Theoretical and experimental investigations of the potential of osmotic energy for power production, Membranes, 4 (2014) 447-468.

[6] A. Efraty, Pressure retarded osmosis in closed circuit: a new technology for clean power generation without need of energy recovery, Desalination and Water Treatment, 51 (2013) 7420-7430.

[7] R.L. McGinnis, J.R. McCutcheon, M. Elimelech, A novel ammonia-carbon dioxide osmotic heat engine for power generation, Journal of Membrane Science, 305 (2007) 13-19.

[8] A. Altaee, A. Sharif, Pressure retarded osmosis: Advancement in the process applications for power generation and desalination, Desalination, 356 (2015) 31-46.

[9] S. Loeb, Large-scale power production by pressure-retarded osmosis, using river water and sea water passing through spiral modules, Desalination, 143 (2002) 115-122.

[10] A. Altaee, A. Sharif, G. Zaragoza, N. Hilal, Dual stage PRO process for power generation from different feed resources, Desalination, 352 (2014) 118-127.

[11] A. Altaee, G. Zaragoza, A. Sharif, Pressure retarded osmosis for power generation and seawater desalination: Performance analysis, Desalination, 344 (2014) 108-115.

[12] Y.C. Kim, M. Elimelech, Potential of osmotic power generation by pressure retarded osmosis using seawater as feed solution: Analysis and experiments, Journal of Membrane Science, 429 (2013) 330-337.

[13] T. Thorsen, T. Holt, The potential for power production from salinity gradients by pressure retarded osmosis, Journal of Membrane Science, 335 (2009) 103-110. 
[14] M. Kurihara, M. Hanakawa, Mega-ton Water System: Japanese national research and development project on seawater desalination and wastewater reclamation, Desalination, 308 (2013) 131-137.

[15] Avi Efraty, Closed Circuit PRO Series No 5: clean energy generation from seawater and its concentrates by CC-PRO without need of energy recovery, Journal Desalination and Water Treatment, V 57 (2016), 8035-8049

[16] S. Loeb, Energy production at the Dead Sea by pressure-retarded osmosis: Challenge or chimera?, Desalination, 120 (1998) 247-262.

[17] Avi Efraty, Closed circuit PRO series No 4: CC-PRO hydroelectric power generation prospects from the Red Sea brine and Dead Sea salinity gradient, Journal Desalination and Water Treatment Volume 55, 2015 - Issue 8, Pages 1983-1997 | Received 21 Jan 2014, Accepted 31 May 2014, Published online: 08 Sep 2014.

[18] A. Achilli, T.Y. Cath, A.E. Childress, Power generation with pressure retarded osmosis: An experimental and theoretical investigation, Journal of Membrane Science, 343 (2009) 42 52.

[19] Ali Altaee, Guillermo Zaragoza, Enrico Drioli, John Zouh, Evaluation the Potential and Energy Efficiency of Dual Stage Pressure Retarded Osmosis Process, Applied Energy, V 199 (2017), 359-369

[20] A. Altaee, G. Zaragoza, H.R. van Tonningen, Comparison between Forward OsmosisReverse Osmosis and Reverse Osmosis processes for seawater desalination, Desalination, 336 (2014) 50-57.

[21] http://en.wikipedia.org/wiki/Dead Sea salt, in, Accessed 16th December, 2015. [22] W.A. Phillip, J.S. Yong, M. Elimelech, Reverse draw solute permeation in forward osmosis: Modeling and experiments, Environmental Science and Technology, 44 (2010) $5170-5176$.

[23] G.D. Mehta, S. Loeb, Internal polarization in the porous substructure of a semipermeable membrane under pressure-retarded osmosis, Journal of Membrane Science, 4 (1978) 261-265. 